SEÇÃO TEMÁTICA: EXPERIÊNCIAS DE ENSINO SUPERIOR ALTERNATIVO

\title{
Experiências em Ensino Autônomo de Artes no Reino Unido, 2010-até o presente
}

\author{
Richard Hudson-Miles' \\ 'De Montfort University, Leicester - Reino Unido
}

RESUMO - Experiências em Ensino Autônomo de Artes no Reino Unido, 2010-até o presente. Este artigo examina e contextualiza criticamente a recente onda de escolas de arte autônomas fundadas no Reino Unido a partir da Independent Review of Higher Education Funding \& Student Finance, ou revisão Browne. Discute que estas instituições foram constituídas como uma resposta direta a esta política econômica e à economização neoliberal mais ampla do ensino superior. Com base no trabalho do Edu-Factory Collective e na teoria marxista autonomista que inspirou seu projeto, este artigo discute que estas novas escolas de arte alternativas podem ser compreendidas como instituições autônomas comuns. Além disso, que representam alternativas genuinamente viáveis à prestação estatal mercantilizada, monetarizada e comercializada. Finalmente, com base no trabalho de Santos, são analisadas três escolas de arte alternativas (The Other MA, Southend, Reino Unido; The School of the Damned, Londres, Reino Unido; @.ac, Reino Unido) como formas nascentes da pluriversidade polifônica.

Palavras-chave: Novas Escolas de arte alternativas. Neoliberalismo. Marxismo. Pluriversidade Polifônica.

ABSTRACT - Experiments in Autonomous Art Education in the UK, 2010-Present. This paper critically surveys and contextualises the recent wave of autonomous art schools established in the UK since the Independent Review of Higher Education Funding \& Student Finance, or Browne Review. It argues that these institutions have been formed as a direct response to this economic policy and the broader neoliberal economisation of higher education. By drawing upon the work of the Edu-Factory Collective, and the Autonomist Marxist theory that inspired their project, this paper argues that these new alternative art schools can be understood as 'common autonomous institutions'. Furthermore, that they represent genuinely viable alternatives to the commodified, financialised, and marketised state provision. Finally, drawing upon the work of Santos, three alternative art schools (The Other MA, Southend, UK; The School of the Damned, London, UK; @.ac, UK) are analysed as nascent forms of the polyphonic pluriversity. Keywords: New Alternative Art Schools. Neoliberalism. Marxism. Polyphonic Pluriversity.

Educação \& Realidade, Porto Alegre, v. 46, n. 4, el18205, 2021. 
Experiências em Ensino Autônomo de Artes no Reino Unido, 2010-até o presente

\section{Introdução}

Este artigo examina e contextualiza criticamente a recente onda de escolas de arte autônomas fundadas no Reino Unido a partir da Independent Review of Higher Education Funding \& Student Finance, ou Revisão Browne (Department for Business, Innovation, and Skill [DBIS], 2010). Esta revisão propôs numerosas reformas ao financiamento do ensino superior, que foi discutido como financeiramente insustentável. Depois da revisão, as bolsas de estudo com financiamento estatal foram substituídas por empréstimos estudantis e as bolsas em bloco do Estado para as universidades foram extintas. Os cursos prioritários, como ciências, tecnologia, engenharia e matemática [STEM, no acrônimo em inglês] mantiveram algum financiamento estatal. Atualmente existem propostas para desinvestir até $50 \%$ do financiamento atual dos cursos de artes no ensino superior em prol dos cursos de ciências e tecnologia, considerados economicamente mais producentes (Harris, 2021). Para compensar a diminuição dos ganhos, foi permitido que as instituições triplicassem o valor das taxas de matrícula para graduação, inicialmente para $£ 9.000$ ao ano. Com a inflação, o limite das taxas subiu para £9.250 (US\$12.815) ao ano para estudantes britânicos/da União Europeia. Atualmente, as instituições se tornaram quase inteiramente dependentes destas taxas de matrícula mais elevadas, especialmente aquelas oriundas do lucrativo mercado estudantil ultramarino, do qual as instituições podem cobrar qualquer valor até $£ 38.000$ (US\$52.600) ao ano ou até £61.435 (US\$85.058) para cursos de medicina. O superinvestimento em prédios de grife e projetos de expansão de capital durante um breve período de expansão pós-Browne deixou muitas universidades codependentes com o regime de taxas inflado, significando ser improvável e politicamente tóxico haver uma redução de taxas a níveis pré-2010. O então líder de oposição, Jeremy Corbyn, foi publicamente ridicularizado por sugerir, como parte de sua campanha eleitoral em 2017, que o esquema de taxas corrente deveria ser abolido e que a dívida estudantil pode precisar ser perdoada (Ferguson, 2017 in Full Fact, 2017). No entanto, as taxas de matrícula continuam congeladas devido à pressão política sobre o atual governo conservador. Estas pressões são tanto externas, oriundas de grupos da campanha estudantil e oponentes políticos (HC Deb, 2020), como internas, da própria Fazenda do governo, que está questionando seriamente a sustentabilidade em longo prazo do sistema de empréstimo estudantil (Morgan, 2021b). A recente crise da COVID-19, que resultou no cancelamento do total do ensino universitário presencial, ampliou as pressões de ambos os lados (HC Deb, 2020). O documento Post-18 Review of Education and Funding, ou Revisão Augar (2019), recentemente publicado pelo Ministério da Educação, contém propostas para uma redução geral no limite das taxas a $£ 6.500$ ao ano, taxas diferenciais baseadas na qualidade da prestação ou negativa de concessão para cursos de "baixo valor" (Augar Review, 2019, p. 135). A controvérsia destas propostas, juntamente com uma mudança de Primeiro-Ministro e de Ministro da Educação desde que a revisão 
foi encomendada, pode significar que as recomendações Augar sejam postergadas para sempre ou simplesmente ignoradas (Morgan, 2021a).

Em resposta direta às reformas da Revisão Browne, a partir de 2010 foram fundadas inúmeras escolas de arte autônomas, orientadas para os estudantes e totalmente gratuitas. Algumas destas instituições existem unicamente para oferecer acesso ao ensino superior em artes àqueles que já não conseguem arcar com as taxas de matrícula. Outras se consideram uma explícita "subversão da atual corrupção monetária do sistema educacional' (School of the Damned, 2015). Muitas se estabeleceram como alternativas legítimas à academia neoliberal. A conceituada exposição New Contemporaries ${ }^{1}$, considerada uma das principais plataformas para os melhores artistas egressos, agora reconhece programas de escolas de arte alternativas como equivalente à oferta convencional ao avaliar inscrições para ingresso estudantil. A maioria destas instituições experimentais tem presença na web, através da qual vem se estabelecendo uma montagem de ofertas alternativas, juntamente com um arquivo digital ad hoc de pedagogia crítica de artes. Entretanto, estas organizações carecem de uma rede ou estrutura formal. Um "Festival de Ensino Alternativo de Artes", organizado pela artista-pesquisadora Sophia Kosmaoglou (2021a), almejava facilitar o intercâmbio de conhecimento entre escolas de arte alternativas e representava o primeiro passo para organizar estas instituições em uma rede. Infelizmente, o evento foi adiado devido à crise do coronavírus. Este artigo está embasado no trabalho de Kosmaoglou e representa a primeira tentativa de mapeamento destas escolas de arte experimentais na literatura acadêmica. Além de documentar estas instituições para registro histórico, este artigo objetiva destacar os desafios políticos e pedagógicos colocados para o ensino superior convencional. Elaborado para um público internacional, este artigo interpreta criticamente estas escolas de arte autônomas através da lente das teorias globais da pedagogia crítica. Especificamente, está embasado no recente trabalho do Edu-Factory Collective (2009), especialmente suas propostas para uma universidade global autônoma. Também utiliza as categorias de Santos (2018) - universidade polifônica, subversidade e pluriversidade para mapear os vários modelos alternativos de escolas de arte. Espera-se que o exercício de mapeamento contido neste artigo possa contribuir para a organização desta multidão nascente (Hardt; Negri, 2006) de educadores alternativos de arte e para ampliar sua voz além do Reino Unido. Em termos mais gerais, este artigo constitui uma contribuição às lutas universitárias do mundo inteiro e uma tentativa de auxiliar na formação da universidade autônoma global, ou pluriversidade.

\section{A Economização do Ensino Superior Britânico}

No Reino Unido, as taxas de matrícula do ensino superior foram introduzidas em 1998, sob o governo trabalhista de Tony Blair. Na época, foi solicitado que os estudantes pagassem uma taxa inicial suplementar de $£ 1.000$ como contribuição para os custos de sua educação 
Experiências em Ensino Autônomo de Artes no Reino Unido, 2010-até o presente

(Bolton; Hubble 2018). Esta quantia aumentou para £3.000 em 2006, sob o governo trabalhista remodelado de Blair, e foi introduzido um sistema de empréstimo estudantil adiado. O sistema de empréstimo estudantil do Reino Unido difere dos Estados Unidos por continuar dependente da renda, sendo solicitado aos estudantes que façam seu reembolso apenas quando sua renda ultrapassar um limiar específico. Atualmente esta quantia é £27.295 por ano, £2.274 por mês ou £524 por semana (UCAS, 2021). O sistema de empréstimo no estilo hipoteca dos Estados Unidos é baseado em reembolsos mensais fixos, significando que a pressão pelo reembolso aumenta com qualquer diminuição na renda do egresso (Barr et al., 2019, p. 33). Embora o sistema britânico no estilo de imposto ao egresso seja indiscutivelmente mais justo para os estudantes, também aumenta a probabilidade de inadimplência. Atualmente, os reembolsos de empréstimo estudantil pendentes são perdoados inteiramente após 30 anos (Bolton e Hubble 2018: 4). As estimativas do governo sugerem que somente $25 \%$ dos atuais estudantes irá quitar seu empréstimo (Bolton, 2021). Consequentemente, o empréstimo estudantil é uma dívida pública insustentável e exponencialmente crescente, subsidiada de fato pelo contribuinte. Para resolver este problema, em dezembro de 2017 e em dezembro de 2018 o Tesouro Público vendeu duas frações de empréstimos estudantis dependentes da renda para empresas de investimento privado (Bolton; Hubble 2020). Atualmente, as propostas para modificar os termos de empréstimo favoráveis que os estudantes inicialmente assinavam estão sendo debatidos.

Barr (2016) localizou a lógica econômica do sistema de empréstimo estudantil no trabalho de Milton Friedman (1945; 1955), especificamente suas teorias de investimento de capital humano. Friedman discutia que o investimento estatal no capital humano gerava retornos econômicos maiores do que o capital humano. Ainda mais, que o ensino médio e superior representavam uma importante forma deste investimento em termos nacionais. Para Friedman, a escolha entre um sistema de ensino superior em massa financiado pelo contribuinte e um de elite ou seletivo poderia ser suplantada por uma terceira via, que suplementava o financiamento público com o privado. Friedman propôs que os indivíduos poderiam vender ações de sua possível renda futura como contrapartida pelos custos imediatos de sua formação. Isto pode ser compreendido como o precursor do empréstimo estudantil dependente da renda (Barr, 2016), cujo pensamento econômico figura como um investimento privado, usado em relação ao potencial de ganhos futuros. No Reino Unido, a era pós-Browne arraigou a ideologia do ensino superior como investimento privado em capital humano, ao invés de um bem público ou social. O aumento dos honorários disfarçavam o que McGettigan (2013) descreveu como experiência camuflada na reforma educacional neoliberal. Juntamente com a imposição de um maior ônus financeiro sobre os estudantes, impedindo o acesso à universidade daqueles economicamente desfavorecidos, estas reformas aceleraram a monetarização, a comercialização e a mercantilização (McGettigan, 2013) da universidade britânica. Estas reformas podem ser considera- 
das como neofriedmanianas, projetadas não apenas para substituir o financiamento público pelo privado, mas também para permitir que novos prestadores privados com fins lucrativos ingressassem no mercado. Uma consequência evidente desta comercialização é que agora os estudantes em geral são considerados consumidores de educação e as universidades como serviços ao consumidor. Fundamentalmente, isso reconfigurou a relação entre universidades, cidadãos e o Estado.

Para Wendy Brown (2015, p. 21-45), a "economização” do ensino superior tem consequências além da universidade. Ao figurar a sociedade como a totalidade de capitais humanos concorrentes, a igualdade deixa de ser o princípio central da democracia e a "desigualdade se transforma em normal, até mesmo normativa” (p. 35). Além disso, a ênfase na responsabilidade individual e no investimento privado cauteloso retira a ênfase das ideias sociopolíticas de ajuda mútua, de solidariedade, de contrato social e de concepções coletivas de "classe, trazendo consigo a base analítica para alienação, exploração e associação entre trabalhadores" (p. 38). Essa economização transforma o "homo-academicus" e o "homo-politicus" em "homo-oeconomicus". Quando tudo é traduzido em termos puramente econômicos, "a base desaparece para a cidadania preocupada com a coisa pública e o bem comum” (p. 39).

A lógica da economização coopta igualmente o "homo-aestheticus" e já tem tido efeitos visíveis sobre os cursos de artes e humanidades no Reino Unido. Considerados como cursos não prioritários em termos nacionais, o desinvestimento de financiamento não apenas privatizou de fato a prestação de escolas de arte do país de um golpe só (McQuillan, 2010), mas também originou uma guerra da cultura nascente de ilk Readings (1996) reconhecido na era Reagan nos Estados Unidos. Cada vez mais os cursos de artes e humanidades são rotulados como de baixo valor pobre para o dinheiro em comparação com aqueles com itinerários de carreira mais lucrativos. As Revisões Browne e Augar empregam esta retórica, usando repetidamente o significante "cursos prioritários" para implicitamente diferenciar os cursos STEM dignos de apoio continuado limitado. Estes discursos compreendem valor unicamente com base no salário projetado do egresso (McGettigan, 2016). Os cursos de artes são especialmente considerados de baixo valor para o dinheiro devido à maior probabilidade de os estudantes de artes deixarem de pagar seus reembolsos de empréstimo. Os números do Institute for Fiscal Studies [IFS] sugerem que os egressos de cursos de artes custam $30 \%$ a mais para o contribuinte do que os cursos de engenharia (Busby, 2019). Este discurso negativo vem resultando em um declínio visível no ingresso em cursos de artes e humanidades em comparação com outros cursos (Woolcock, 2021; British Academy, 2018; O’Leary, 2018). 
Experiências em Ensino Autônomo de Artes no Reino Unido, 2010-até o presente

Figura 1 - Ganhos projetados de egressos no Reino Unido, organizados por curso

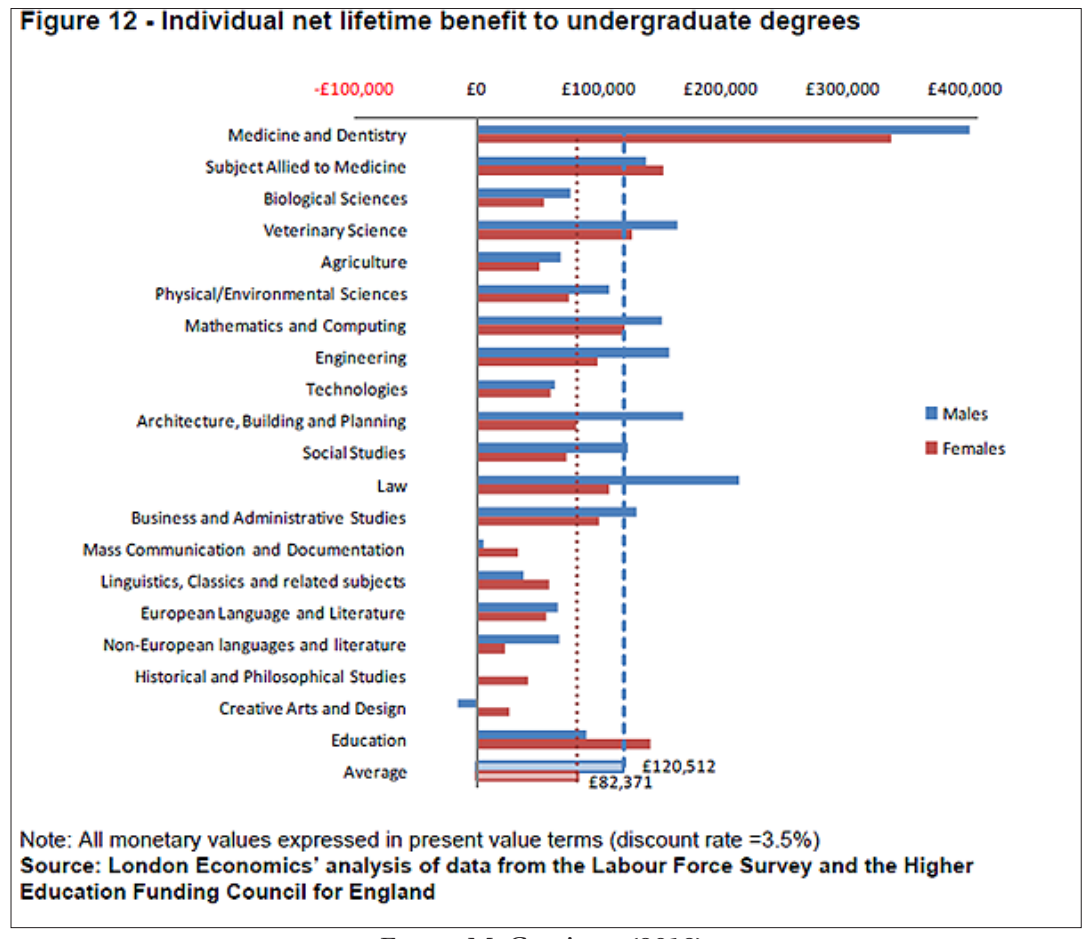

Fonte: McGettigan (2016).

Relatórios recentes do Russell Group (2020; 2015), que representa as vinte e quatro universidades de elite e, portanto, as mais seletivas do Reino Unido com exceção de Oxford e Cambridge, reconhecem as barreiras persistentes ao ensino sob economização para aqueles socialmente desfavorecidos. Um achado é que as maiores pressões financeiras estão desincentivando os estudantes mais pobres a escolherem universidades localizadas fora de sua cidade natal. Portanto, o futuro destes estudantes é determinado pela oferta da universidade local. A remoção da oferta de artes das universidades provinciais tem impacto além da redução de escolha para o consumidor. Conforme Beck e Cornford (2014) discutiram, isso também representa a eliminação da ideia subcultural e negacional da escola de artes do imaginário cidadão. Além da remoção de um importante catalizador para indústrias criativas locais, a função cidadã perdida da escola de artes pode ser compreendida como a ausência de um "desafio" crítico "ao cotidiano" (2014, p. 8).

Isso é meramente um efeito daquilo que Jeffrey Williams chamou de pedagogia da divida (Williams apud Edu-Factory Collective, 2009). Ao escrever sobre o modelo norte-americano de ensino superior, indiscutivelmente sob maior economização me termos mundiais, ele discute que o ensino superior embasado na dívida instila o receio do fracasso. Orientado por uma aguda ansiedade a respeito das consequências 
financeiras de más escolhas de universidade, isto impede escolhas de cursos arriscadas, como as artes. Este receio do fracasso é internalizado como uma lição na escolha da carreira, descrita por Mark Fisher (2009) como realismo capitalista. No primeiro caso, rotula os cursos de artes tanto como mau investimento e diletantismo privado para as classes burguesas. No segundo, insiste que "nada na vida é anterior ao mercado" e que nada é grátis na vida (Williams apud Edu-Factory Collective, 2009, p. 95). Aqui, é responsabilidade cidadã implicada nas universidades oferecer cursos economicamente produtivos e dever cidadão dos estudantes aumentar o sistema econômico hegemônico ao reembolsar suas dívidas pessoais no tempo certo. Uma possibilidade preocupante levantada pelos recentes números do Tesouro Público descobertos por McGettigan (2016) é que muitos egressos das artes nunca receberão o suficiente para quitar seus empréstimos. É altamente provável que a constante e crescente taxa de inadimplência force o governo a negar acesso a empréstimos para estudantes de artes no futuro, ou no mínimo imponha limitações institucionais estritas ao número de estudantes.

Outra consequência da economização do ensino é abordada por um relatório recente em coautoria entre a National Union of Students e o grupo de universidades do Reino Unido, que representam as antigas politécnicas às quais a maior parte das escolas de arte britânicas foi incorporada de $1992 \mathrm{em}$ diante. Este relatório foi intitulado Breaking Down the Barriers to Student Opportunities and Youth Social Action (2015). Sua ambição declarada era explorar como os estudantes poderiam ser incentivados a participar de suas comunidades locais por meio de voluntariado e outras formas de trabalho comunitário. O objetivo é assegurar que o ensino superior britânico atenda às necessidades da comunidade ampliada. Aqui, ser voluntário é considerado como uma maneira para os estudantes devolverem algo para a região onde vivem e estudam. Este relatório insiste na centralidade da universidade para a sociedade civil:

As origens de ensino superior remontam a quase um milênio; muitas universidades foram criadas por cidadãos, comunidades e suas sociedades com uma perspectiva de contribuir para a transformação social e econômica, e a esta função cidadã continua igualmente relevante hoje (NUS/UUK, 2015).

O paradoxo é que a universidade em economização e sua estrutura de taxas proibitivas queima as pontes sociais que depois sugere aos estudantes que devem reconstruir mediante do trabalho voluntário. Louis Althusser (1971) discutido notoriamente que a ideologia pode ser definida como a relação imaginária com as condições reais de produção. Esta fantasia do papel social e comunitário da universidade, acima e além de sua função econômico-disciplinar, é perfeitamente consistente com a análise de Althusser. Embora não cite o pelo nome, o ensaio de Williams retoma Althusser ao efetivamente discutir que a universidade orientada pela dívida mantém a hegemonia como um "aparelho ideológico do estado" [AIE] (Althusser, 1971, p. 143). 


\section{Rumo a uma Universidade Autônoma Global}

O ensaio de Williams foi publicado em um volume de trabalhos de pedagogia crítica escritos sob o nom de guerre do Edu-Factory Collective (2009). Este coletivo agora-disperso contava uma vez com mais de quinhentos integrantes. Originou-se dos debates em um fórum de discussão na internet, criado para coordenar ativistas que operam em lutas universitárias globais. Alguns deles participaram dos protestos estudantis italianos contra as reformas neoliberal Gelmini do ensino superior italiano. Gradativamente, estes protestos coalesceram na Rete por o l'Autoformazione / Rede para Autoeducação. Este grupo transformou um movimento de protesto on line, fomentado em fóruns de discussão moderados por docentes universitários precarizados, em um programa formal de cursos autônomos de autoinstrução on line (Parar Bolonha, 2007). Esta ênfase na autonomia e na autoeducação evidencía a extensão em que a política de Autonomia e operaismo sustentam muito do trabalho do Edu-Factory Collective. Para os não familiarizados, Autonomia era um movimento político autonomista, extra-parlamentar, pós-marxista, ativo na Itália no fim da década de 1970, "formado quase inteiramente por intelectuais e jovens trabalhadores e jovens desempregados" (Lotringer; Marazzi, 2007, p. v). Autonomia surgiu como uma facção dissidente da militância operária, como parte do movimento político italiano mais geral chamado operaismo [trabalhismo]. Como muitos dos movimentos que surgiram depois dos levantes globais de 1968, a Autonomia rejeitava as formas tradicionais de organização política comunista, que eram figuradas como repressoras. Ao contrário, enfatizava uma cultura política experimental baseada na organização rizomática, na espontaneidade e na criatividade. Atualmente, trabalhismo é comumente empregado como pejorativo contra a idealização esquerdista da classe trabalhadora, como na propaganda soviética ou na arte socialista realista. Na Itália, entretanto, o trabalhismo tinha um significado diferente, referindo-se à reorganização de instituições da classe trabalhadora para controle democrático direto (Ryder, 2017). Esta estratégia pretendia contribuir tanto para a conscientização da classe trabalhadora como para a democratização mais geral da sociedade de baixo para cima. Ao invés de valorizar o trabalho, os trabalhistas defendiam a emancipação dos trabalhadores da penosidade das linhas de produção. O movimento trabalhista italiano foi teorizado nos artigos de dois importantes periódicos. Primeiro, em Quaderni Rossi [Cadernos Vermelhos] (1961-5), e depois em Classe Operaia [Classe Trabalhadora] (1963-6), ambos fundados pelos marxistas autonomistas Antonio Negri e Mario Tronti. Um dos conceitos chave debatidos em ambos era o conceito de fábrica social de Tronti (2013 [1962]). Defendia que a tendência do Estado de atura cada vez mais como um capitalista concentrado, coletivo levou a lógica de relações capitalistas de produção a permearem todos os aspectos da sociedade. Aqui, toda a produção social é transformada em produção industrial (Tronti, 2013 [1962]), e a sociedade é, consequentemente, semelhante a uma fábrica social abrangente. Um 
exemplo simples seria a descrição agora naturalizada de setores de arte contemporânea como indústrias criativas - um termo que os trabalhistas iriam achar contraditório. A economização da universidade em uma empresa capitalista privada é outro exemplo.

O Edu-Factory Collective começa seu trabalho a partir da proposição de que "como era a fábrica, assim é a universidade agora" (2009, p 125). Seu livro mais importante, Towards a Global Autonomous University (2009), contém um posfácio de Negri em coautoria com Judith Revel (172-179). Este ensaio define a "instituição autônoma comum (IAC) ou uma organização autônoma multitudinária” (p. 173). A IAC é uma extensão das Instituições de Trabalhadores Autônomos [ITA] desejadas pelos trabalhistas. As ITAs podem assumir muitas formas, mas são sintetizadas nas tentativas de colocar as fábricas sob controle dos trabalhadores no fim da década de 1960 e começo da década de 1970. Os principais exemplos são a planta petroquímica em Porto Marghera, a fábrica da Fiat em Turim ou a fábrica de relógios LIP em Besançon. As ITAs se caracterizam por sua organização política autônoma, que é independente de líderes, patrões ou partidos políticos. Também são identificadas por sua capacidade de garantir uma voz política para seus atores. Mais importante ainda, sua formação deve ser compreendida como um "processo de autoaprendizagem, de baixo para cima" (Negri; Revel in Edu-Factory Collective, 2009, p. 172). A IAC é uma tentativa de atualizar o conceito de ITA para a época contemporânea, que se deslocou da produção fabril fordista para um sistema pós-fordista de trabalho imaterial (Lazzarato, 1996). Consequentemente, a IAC é "baseada no novo horizonte relacional (comunicativo, informática etc.) que é característico do novo modo de produção" (p. 173). Como muitas formas de organização social orgânica na era da internet, a IAC tende a ser organizada horizontalmente, em rede, nômade, "expansiva, mas também dissipadora” (Lazzarato, 1996). As IACs resistem a tendências políticas normativas e ao processo de institucionalização que transformam a horizontalidade em novas estruturas verticais de poder. Nascido de debates heterogêneos por ativistas dentro de lutas universitárias globais, o Edu-Factory Collective representa uma tentativa de reconstruir a universidade como uma IAC. Seu título coletivo nos convida a questionar se é "possível se organizar na universidade como se fosse uma fábrica", mas além das formas de trabalho organizado tradicionais e "esgotadas", como os partidos políticos (2009, p. 2).

Um sentido desta organização pós-política é esboçado por Stefano Harney e Fred Moten em seu ensaio The University and the Undercommons (Edu-Factory Collective, 2009, p. 145-150). Apesar de publicado originalmente em Towards a Global Autonomous University, posteriormente este texto iria se transformar em um capítulo no importante livro de Moten e de Harney, The Undercommons (2013). Harney e Moten (2013) discutem que "a única relação possível hoje para a universidade é criminosa” (p. 145). O termo undercommons se refere aos espaços subterrâneos sob a universidade em economização onde esta criminalidade é gestada e organizada. Por criminalidade, Harney e Mo- 
Experiências em Ensino Autônomo de Artes no Reino Unido, 2010-até o presente

ten querem dizer a reorientação da docência para longe do paradigma da mercantilização, rumo a sua capacidade social. A lógica da economização só consegue esta afirmativa em termos de desperdício, se não como lucro explicitamente roubado. Para Harney e Moten, a capacidade social da docência pode ser compreendida como "uma orientação coletiva para o objeto do conhecimento como projeto futuro, e um compromisso com aquilo que queremos chamar de organização profética" (p. 146). Reformulada na língua do autonomismo da década de 1960, além de fabricar valor para a fábrica de conhecimento, a docência também produz um processo intelectual compartilhado e laços sociais rizomáticos. O "além da docência" (Edu-Factory Collective, 2009, p. 147) também é "o devir comum do trabalho" (Hardt; Negri, 2006, p. 103) e as formas embrionárias daquilo que Hardt e Negri denominam de multidão. Em contraposição a concepções de classe redutoras e metapolíticas, a "multidão é uma multiplicidade irredutível; as diferenças sociais singulares que constituem a multidão devem sempre ser expressas e nunca podem ser achatadas em mesmice, unidade, identidade ou indiferença" (Hardt; Negri 2006, p. 105). Da mesma forma, os undercommons da universidade representam uma desidentificação da academia, de suas subjetividades normativas e de ideias hegemônicas do valor da docência. Em contraposição, os undercommons fomentam "a negligência da profissionalização e a profissionalização do acadêmico crítico' (EduFactory Collective, 2009, p. 147).

Harney e Moten se referem aos undercommons como comunidades maroon, transformando em belicoso o termo histórico para as sociedades ad hoc formadas por escravos fugidos. Estas comunidades maroon representam todos as variadas subjetividades alienadas da universidade neoliberal. Em seu recente livro sobre o assunto, Hall (2018) identificou branquitude e masculinidade como as normas tóxicas e hegemônicas rumo às quais a universidade interpela todos os seus atores. Para Hall (2018, p. 206), recusar "[...] o movimento da mercadoria acadêmica como um movimento da negação da subjetividade humana" também é enfatizar as "interseções generificadas, racializadas e de classe" do sujeito da universidade. Similarmente, entre os inúmeros undercommons, Harney e Moten listam "estudantes sem mentores, historiadores adjuntos marxistas, professores de gestão queer ou assumidos, departamentos de estudos étnicos de faculdades estatais, programas de cinema encerrados, estudantes iemenitas editores de jornal com visto expirado, sociólogos de faculdades historicamente negras e engenheiras feministas" (p. 149). Esta lista de subjetividades interseccionais poderia ser expandida indefinidamente. Este trabalho de desconstrução reitera a diferença no próprio ponto em que é cooptado pela universidade em economização em novidades ou tokenism do currículo, todos sendo cinicamente anunciados como uma oferta estudantil melhorada. Ao citar vozes pós-coloniais como C. L. R. James e Stuart Hall, o ensaio dos estudiosos anglo-asiáticos Nirmal Puwar e Sanjay Sharma ShortCircuiting the Production of Knowledge (Edu-Factory Collective, 2009, p. 45-49) discute que a retórica da inclusão esposada pela universida- 
de neoliberal disfarça uma forma de assimilação cultural. Para Puwar e Sharma, "a educação neoliberal está acolhendo a diferença cultural para um capitalismo multicultural em expansão” (p. 46). De maneira semelhante, o ensaio Global Assemblages vs. Universalism, de Aihwa Ong (Edu-Factory Collective, 2009, p. 39-41) identifica um ponto cego eurocêntrico à interseccionalidade negra em conceitos tanto de universidade global como de noções ativistas dos undercommons. Contra processos centrípetos de assimilação, o undercommons de Harney e Moten é um espaço centrífugo onde um "iluminismo fugitivo representa o criminoso, o matricida, o queer, na cisterna, no andar da vida roubada, a vida roubada pelo iluminismo e roubada de volta, onde os comuns dão refúgio, onde o refúgio gera comuns" (Edu-Factory Collective, 2009, p. 147). À lista potencialmente infinita de interseccionalidades aberrantes acima, para fins deste ensaio é importante acrescentar, pelo menos, a não empregabilidade de egressos de Belas Artes, pesquisadores em arte baseados na prática e historiadores da arte queer ou BIPOC [pretos, indígenas e pessoas de cor, no acrônimo em inglês].

O Edu-Factory Collective pode ser alternadamente compreendido como uma plataforma para os undercommons, uma IAC ou uma multidão nascente. Em suas próprias palavras, representava um mecanismo para impregnar "formas específicas de resistência [a,] e a organização de rotas de fuga” (p. 1), da universidade neoliberal. É "um espaço onde as lutas se conectam, um espaço de [...] de experiências organizacionais" (p. 3). Aqui, a pesquisa é compreendida não como produtos quantificáveis medidos em auditorias de pesquisa, mas como "prática teórica” (p. 1) partidária e subversiva”, no sentido althusseriano (1965). O Edu-Factory Collective concebe a docência como uma práxis política, não meramente o trabalho afetivo dos setores de serviços da fábrica de conhecimento. Conforme seu irônico título sugere, o Edu-Factory é ao mesmo tempo um reconhecimento da degeneração da universidade em um AIE na fábrica social, mas também um movimento de resistência global, além de Estados e poderes institucionais específicos. Readings (1996), que é repetidamente citado pelo coletivo, discutia que a ruína da universidade deve ser compreendido como consequência tanto da globalização como da ausência resultante de um ideal de universidade unificadora, além de conceitos técnico-burocráticos como excelência. Além da economização, o Edu-Factory Collective discute que "a crise da universidade foi determinada por movimentos sociais em primeiro lugar" (Edu-Factory Collective, 2009, p. 1). Estes movimentos sociais, pelo menos na era moderna, encontram seu apogeu nas lutas universitárias globais de 1968. Hoje, as lutas da universidade têm um sotaque cada vez mais pós-colonial, evidente nos protestos Rhodes Must Fall que começaram na Cape Town University, na África do Sul (2015), e que se propagaram para a Oxford University, no Reino Unido. Os protestos com tema único como estes têm se transformado organicamente em clamores coletivos para decolonizar a universidade (Grant; Price, 2020; Arday; Mirza, 2018). Depois do cancelamento do ensino presencial durante a pandemia da COVID-19, estas lutas interseccionais são cada vez mais 
Experiências em Ensino Autônomo de Artes no Reino Unido, 2010-até o presente

organizadas em conjunto com greves de pagamento de aluguel e boicote ao pagamento de taxas, em uma multidão aparentemente crescente de protestos estudantis, semelhantes aos de 1968. Embora precedam estes eventos, muitos dos vários exemplos de autoeducação experimental discutidos durante todo seu livro são produzidos diretamente nas lutas de grupos de ativistas da universidade, muitos dos quais são vozes decoloniais do Sul global.

Aqui se inclui o Vidya Ashram em Varanasi, Índia², que é um retiro comunitário dedicado ao desenvolvimento de lokvidya (saber popular) indígena. Isto é considerado uma forma de resistência à exploração econômica do conhecimento pela sociedade industrial, e como uma forma de resistência contra a tecnocracia, o cientificismo e o imperialismo epistemológico ocidental (Edu-Factory Collective, 2009, p. 167). Lokvidya é o conhecimento que não tem nenhum valor econômico direto para os capitalistas ou que opera sobre as margens do mercado, ou o trabalho oculto que não obstante é explorado como mais-valia pelo capital. Os exemplos de lokvidya incluem o trabalho doméstico feminino e as práticas agrárias de tribos indígenas em vilarejos remotos. O Vidya Ashram se dedica a oferecer uma plataforma para desenvolver estes saberes e divulgá-los por meio de oficinas públicas, ensino presencial, acampamentos de jovens e outras atividades pedagógicas projetadas para facilitar o diálogo entre educadores, ativistas e comunidades indígenas ou camponesas. Ao se apropriar do termo usado pela campanha de Gandhi de resistência não violenta contra o colonialismo britânico, o Vidya Ashram considera sua atividade como "satyagraha de saberes" - uma forma pacífica, porém contra-hegemônica de não-cooperação com a Edu-Factory branca, ocidental, em economização (p. 169).

Publicado após a dissolução do Edu-Factory Collective, o importante livro de Santos, The End of The Cognitive Empire (2018) dá continuidade de muitas maneiras o projeto global de universidade autônoma. Sugere quatro modelos pedagógicos críticos pelos quais uma universidade decolonial ou contra-hegemônica emergente pode ser identificada e compreendida: a universidade comprometida, a universidade polifônica, a subversidade e a pluriversidade. Nesta exata ordem, estas categorias conceituais descrevem um movimento de distanciamento da universidade como AIE althusseriano e rumo a uma universidade freireana de libertação. A universidade comprometida é uma instituição política, dedicada a uma ideologia política unificadora. Estas instituições podem ser, mas não automaticamente, emancipatórias. Elas continuam repressoras se sua ideologia abrangente se tornar dogmática ou for seguida de maneira acrítica. Conforme está implicado em seu nome, a universidade polifônica estaria atenta a uma multidão de vozes, o que, seguindo Ong e Puwar, e Sharma (em Edu-Factory Collective, 2009), não é simplesmente dizer que é uma instituição de diversidade ou inclusividade multicultural. Ao contrário, a universidade polifônica é "composta por vozes que são expressas de maneira convencional e não convencional, tanto em processos de aprendizagem orientados para a graduação como não" (Santos, 2018, p. 277). Embora cada 
vez mais a universidade neoliberal esteja falando em polifonia da boca para fora em seu rol de programas de acesso, de setores de auxílio financeiro e estímulos ao recrutamento dirigido, a polifonia deve ser compreendido como uma força que excede estas estratégias instrumentais. Para a universidade em economização, a diversidade e a inclusão devem ser compreendidas fundamentalmente como o desejo de buscar novos mercados de consumidores para monopolizar. É menos provável uma pluralização de vozes na universidade do que uma assimilação de todas as vozes e diferenças sob uma modalidade hegemônica única de pronúncia recebida. De encontro a isso, Santos descreve a universidade genuinamente polifônica:

\begin{abstract}
A nova universidade polifônica será um lugar onde as ecologias dos saberes irão encontrar um lar e onde os acadêmicos e os cidadãos interessados na luta contra o capitalismo cognitivo, o colonialismo cognitivo e o patriarcado cognitivo colaborem para reunir diferentes saberes com pleno respeito por suas diferenças, ao também procurar por convergências e articulações. Sua finalidade é responder a questões que, apesar de não terem nenhum valor de mercado, são social, politica e culturalmente relevantes para as comunidades de cidadãos e grupos sociais. O lado não mercantilizado da universidade irá se transformar em um novo tipo de universidade popular? Irá produzir um novo tipo de conhecimento pluriversal em que o saber artesanal será levado mais a sério e em que os saberes decoloniais, mestiços irão surgir? (Santos, 2018, p. 280).
\end{abstract}

Compreendida internamente, a polifonia é uma força de diferença, suplemento, autocrítica, ingresso ou a quinta coluna da universidade. Conforme Harney e Moten reconhecem, as tentativas artificiais de fabricar a polifonia na universidade, sob a bandeira do multiculturalismo liberal, poderiam acidentalmente facilitar o desenvolvimento de um "undercommons do Iluminismo" (Edu-Factory Collective, 2009, p. 146) subversivo. Entretanto, existe outro tipo de universidade polifônica fora da academia, "ocupando a ideia de uma universidade e colocando-a para uso contra-hegemônico" (Santos, 2018, p. 277). Este tipo de organização polifônica é descrito como "subversidade"': um neologismo crítico que escreve a experiência do subalterno nas ações do acadêmico subversivo. A "subversidade" é ao mesmo tempo um ato da escrita retroativa para a universidade e de demolição de suas torres de marfim. A "pluriversidade" é a etapa final da emancipação decolonial da universidade. Mesmo assim, é produto de campos de batalha identificáveis na universidade contemporânea. Primeiro, a tensão entre o conhecimento com e sem valor de mercado (Santos, 2018). Em segundo lugar, entre o que Santos denomina de pesquisa abissal e pós-abissal. Abissal se refere às epistemologias do Norte, pós-abissal se refere às do Sul. Uma questão chave é a medida em que até mesmo os estudos críticos mais subversivos ou anticapitalistas da universidade continuam enraizados no abissal. Contra a pedagogia crítica abissal, que é ostensivamente subversiva, mas ainda mantém a episteme branca da universidade, "a 
Experiências em Ensino Autônomo de Artes no Reino Unido, 2010-até o presente

pluriversidade tem mais probabilidade de emergir das alianças e das acomodações entre aqueles defensores da busca do conhecimento sem valor de mercado que também são defensores da ciência pós-abissal" (Santos, 2018, p. 278). Embora nem a universidade autônoma global nem a pluriversidade tenham se concretizado, há numerosos sinais de modelos polifônica que surgem globalmente e que poderiam colocar seus alicerces. O restante deste artigo examinará os vários exemplos polifônicos de ensino superior alternativo que surgiram no Reino Unido desde a Revisão Browne (2010). Isso tem o objetivo de documentar os mais significativos deles, além de categorizá-los de acordo com a ontologia de Santos. O que é notável sobre cada um dos exemplos a seguir não é simplesmente que eles reparam as falhas do modelo neoliberal de universidade arruinado, mas que incorporam os valores cidadãos de comunidade, solidariedade, inclusividade e igualdade, que existem para a universidade neoliberal apenas como indicadores chave de desempenho dentro de uma estratégia de marketing, o que também significa dizer no imaginário capitalista.

\section{Escolas deArte autônomas no Reino Unido, 2010-Atéo Presente}

Em resposta aos processos da economização mencionados acima, houve uma onda de oferta alternativa para ensino de artes e humanidades no Reino Unido. Quase a totalidade destas instituições citam as reformas neoliberais promulgadas pela Revisão Browne (2010), ou suas consequências, como o catalizador para sua criação. Embora seja enganoso sugerir que todas estas subversidade nascentes estejam direcionadas para o ensino de artes, a maior porcentagem está. A repetida ambição destas instituições é oferecer acesso gratuito ao ensino de artes para estudantes cujo ingresso seria proibitivo pelos valores de taxas de matrícula mais altos. Alguns consideram isso como uma missão explicitamente política. Outros o consideram como uma forma de ativismo comunitário ou cidadão além de qualquer ideologia política programática.

Apesar do significativo número de escolas de arte alternativas que surgiram no Reino Unido na última década, muito pouca pesquisa acadêmica foi publicada sobre elas. Atualmente, o único livro publicado que se relaciona com este campo é School: A Recent History of SelfOrganised Art Education, de Sam Thorne (2017). A ambição de Thorne é oferecer um mapa de um território, com um foco tão internacional quanto possível. De acordo com isso, os exemplos do Reino Unido são limitados. Seu ensaio introdutório procura examinar a relação da arte de vanguarda com os modelos históricos progressistas de ensino da arte, como Black Mountain College nos Estados Unidos (1933-1957), Bauhaus na Alemanha (1919-1933) e Vkhutemas na URSS (1920-1933). Além destes modelos do início do século XX, Thorne defende a relação de novas escolas de arte alternativas e o que foi chamado de virada pedagógica ou educacional na curadoria de arte internacional. A virada educacional identifica uma tendência nas práticas artísticas contemporâneas 
recentes ou exposições com curadoria de trazer para o primeiro plano o caráter heurístico ou educacional da arte (Rogoff, 2008). A s obras e as exposições da virada educacional ou apresentam explicitamente formas de pedagogia como obras de arte em si ou trazem para o primeiro plano novas formas de relacionalidade, participação ou experiência como espectador como uma crítica artística de modelos educacionais capitalistas e de relações sociais capitalistas. O melhor estudo crítico da arte da virada educacional é Curating and the Educational Turn (2010), de O'Neill e Wilson (2005). Muitos dos artistas associados à virada educacional também são citados no livro de Thorne.

Thorne inicia com uma entrevista com a artista cubana Tania Bruguera, intitulada "outro modelo é possível”. O trabalho recente de Bruguera inclui a transformação da Manchester Art Gallery, Reino Unido (5 de julho de 2019-1º de setembro de 2019) em uma Escola de Integração na qual os cidadãos britânicos poderiam compartilhar experiências com a população imigrante da cidade por meio de uma série de oficinas e aulas gratuitas. Estas aulas incluíam oficinas sobre música clássica hindu, uma introdução à importância dos bolinhos na cultura chinesa e malaia (Manchester tem significativas comunidades chinesas e hindus), aulas para fazer tranças africanas cabelo e aulas de história sobre a arte do protesto. Embora esta não era a intenção declarada, estes tópicos eram exemplos importantes de lokvidya. Antes disso, Bruguera tinha fundado uma escola de artes alternativa na sua cidade natal de Havana. A Cátedra Arte de Conducta (Departamento de Arte do Comportamento - 2002-2009) foi criada como uma peça de arte pública e um espaço de formação alternativa ao sistema de estudos da arte na sociedade cubana contemporânea (Bruguera, 2012). Sua forma representava uma crítica tanto à educação como à sociedade cubana e objetivava ser política, mas não didática. Em Cuba, uma escuela de conducta é uma prisão ou reformatório para menores de 16 anos. O título de Bruguera é projetado para denotar a função disciplinar da educação. Também tinha tentado em vão estabelecer um projeto dentro de uma destas instituições. A Cátedra Arte de Conducta buscava "recuperar parte da história da arte em Cuba que tinha sido suprimida pelo governo" (Bruguera apud Thorne, 2017, p. 63). Ao invés de lecionar em uma instituição formal, as auls ocorriam na casa de Bruguera. O corpo docente incluía artistas profissionais visitantes, mas também "advogados, cientistas, diretores cinematográficos, ex-prisioneiros, donas de casa, jornalistas” (Thorne, 2017, p. 63), todos considerados como úteis para os educadores e facilitadores de práticas de arte contemporânea baseadas na performance.

O livro de Thorne também inclui uma entrevista com o artista britânico contemporâneo Ryan Gander. Gander tinha fundado sua própria escola de artes alternativa, Night School, baseada em seu estúdio em East London. A escola de artes alternativa compreendia uma série de projeções, conversas e atividades sociais, incluindo muitas figuras chave do cenário artístico de Londres. Este arranjo ad hoc recebeu legitimidade do mundo artístico quando a Night School recebeu uma residência no London's Institute of Contemporary Art (abril-setembro de 2011). Desde 
Experiências em Ensino Autônomo de Artes no Reino Unido, 2010-até o presente

então, Gander tem tentado criar uma escola de artes alternativa mais permanente chamada Fairfield International. Estas tentativas de fundar o que seria uma pequena escola de artes residencial na região rural de Suffolk foram frustradas pela recusa dos patrocinadores financeiros de Gander em concordar com um contrato de 25 anos para usar o terreno apenas para finalidades educacionais (Gander; Thorne, 2017, p. 212). Aqui se encontra um problema recorrente com modelos educacionais que procuram existir independentemente do Estado. Por um lado, alguém se torna devedor de investidores financeiros que naturalmente procurariam um retorno em curto prazo para seu investimento ou revertam o projeto por seu real valor imobiliário caso fracasse. Por outro lado, as opções parecem ser a asfixiante burocracia das perpétuas aplicações financeiras, muitas das quais continuam controladas pelo Estado de qualquer maneira. Muito recentemente foi levantada uma terceira possibilidade de financiamento coletivo pelos esforços da ativista Melz Owusu, que arrecadou £60.000 para começar uma Free Black University [FBU]. A FBU objetiva oferecer um currículo totalmente decolonizado orientado para a transformação do mundo através da "imaginação preta radical”". Na época da redação, a FBU existe como um website com currículo e materiais de aprendizagem on line associados. Atualmente o projeto está em um hiato estratégico pelo qual uma estratégia em longo prazo possa ser traçada e o financiamento sustentável garantido. Uma sugestão é que cada universidade convencional pague uma taxa anual para manutenção da FBU como uma forma de reparação por seu papel na continuação da supremacia branca, por meio de seu racismo sistêmico, vínculos históricos com proprietários de escravos e seu papel central na reprodução da episteme colonial do iluminismo (Swain, 2020).

A FBU é um entre 86 exemplos diferentes de antiuniversidades e escolas de arte alternativas documentadas no website pessoal da artista-pesquisadora Sophia Kosmaoglou (2021b). Juntamente com este artigo, esta é a única tentativa acadêmica séria de começar o mapeamento destas instituições. Entre as várias instituições listadas por Kosmaoglou, mais de trinta foram fundadas desde a Revisão Browne de 2010 e se identificam explicitamente como escolas de arte alternativas. Estas instituições variam substancialmente em caráter, desde intervenções autoconscientemente transitórias e efêmeras até aquelas modeladas em maior proximidade com instituições convencionais e aspirando a um status mais permanente. Entretanto, Thorne (2017) discute que compartilham diversas características em comum. Primeiro, as escolas de arte mais alternativas aspiram ao status de parainstituições, existindo como o outro crítico à oferta convencional. Em segundo lugar, a maioria dos projetos é "[...] de pequena escala e ocasionalmente nômades, embora enfatizem uma abordagem ao ensino que é discursiva e colaborativa" (Thorne, 2017, p. 48). Em terceiro lugar, tendem a se organizar em torno de princípios anti-hierárquicos, sendo que muitas rejeitam autoconscientemente as diferenciações entre professores e estudantes. Outro denominador comum é que tendem a ser fundadas por artistas, e menos frequentemente por curadores e por educadores. Finalmente, 
a maioria enfatiza o caráter processual do ensino acima da educação como uma qualificação ou currículo ensinado. A educação, neste sentido, é considerada como uma finalidade em si, não um meio para chegar a um fim. Este caráter heurístico mais do que didático alinha a ideologia destas escolas de arte alternativas com a pedagogia crítica que emergiu durante o século XX. Este artigo defende que cada um dos exemplos citados respeita as definições de IAC de Negri e Revel. Além de enfatizar seu caráter autônomo, a seguinte seção deste artigo irá mapear estas novas escolas de arte alternativas conforme o esquema de Santos. Além da documentação, esta tarefa representa um gesto de solidariedade que possivelmente irá ajudar na futura tarefa de construir a pluriversidade.

Abaixo, as escolas de arte alternativas mais significativas que surgiram no Reino Unido desde a Revisão Browne (2010) serão categorizadas de acordo com sua polifonia específica. Para fins de seleção, o artigo optou por definir a significância como as instituições que atendem a pelo menos dois dos seguintes critérios: 1) têm um website independente ou presença na rede; 2) sua atividade durou muitos anos letivos; 3) foram citadas na literatura secundária; 4) foram incluídas como palestrantes ou delegados para o futuro Festival of Alternative Arts Education. É óbvio que o outro requisito para a seleção é que as instituições devem fundamentalmente prestar educação em artes e operar autonomamente das universidades convencionais. Todos os exemplos foram criados na era pós-Browne. Havia muitos outros exemplos de escolas de arte autônomas comuns antes disso e continuam a operar silenciosamente nos undercommons clandestinos da universidade ou de centros sociais provinciais. A falta da informação publicada sobre estas instituições, o que é deliberado em alguns casos, até mesmo em plataformas de mídia social informais significa que muitas destas instituições passaram despercebidas. Este artigo poderia, portanto, também ser compreendido como um convite ao diálogo para estas instituições e grupos até então invisíveis.

As instituições selecionadas estão listadas no apêndice A e foram subcategorizadas de acordo com três grupos. Os agrupamentos representam uma síntese do esquema de Thorne (2017) e Santos (2018). Foi incluída uma breve descrição da atividade de cada uma, embora o espaço proíba uma justificativa analítica extensa de porque cada uma recai em suas categorias específicas. Ao invés disso, será analisado um exemplo chave de cada tipo de categoria no texto abaixo como ilustração. Seguem-se as três subcategorias. Primeiro, escolas de arte que operam como parainstituições [Escola de Artes Polifônica 1], seja como oferta alternativa para aqueles que não conseguiram acesso por motivos financeiros ou foram forçadas a existir devido ao fechamento de da oferta convencional. A segunda categorização será a escola de artes subversiva [Escola de Artes Polifônica 2], que se coloca explicitamente como contra-hegemônica, anticapitalista ou similar. A última categoria [Escola de Artes Polifônica 3] é reservada para aquelas instituições que se consideram como mais próximas de obras de arte do que escolas de artes. Esta última categoria é a mais próxima daquilo que Harney e 
Moten querem dizer com "o além do ensino"' (Edu-Factory Collective, 2009, p. 147). Aqui, os currículos e os objetivos de aprendizagem formais são abandonados em prol de gestos artísticos especulativos projetados para criar imaginar ensino de artes a instrução da arte além de todas as escolas ou universidades de artes. Paradoxalmente, estas tentativas de dissolução da escola de artes talvez sejam os gestos mais claros para arrastar a escola de artes para fora do abismo. Em conjunto, estas três categorias representam um esboço de uma pluriversidade incompleta por vir. Com base nestes exemplos, a conclusão sugere algo da polifonia necessária polifonia para a concretização da escola de artes pós-abissal.

Figura 2-Instantâneo do vídeo do Toma Manifesto-in-The-Making (2018)

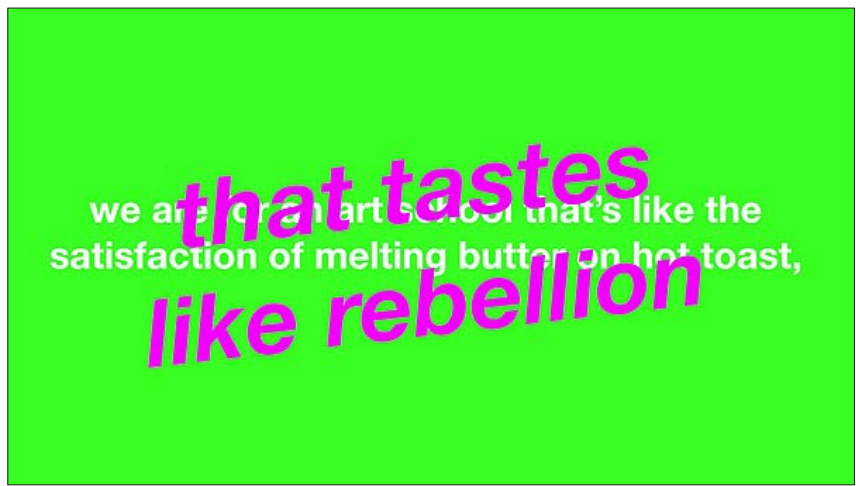

Fonte: Disponível em https://www.toma-art.com/about.

\section{Escola de Artes Polifônica Tipo 1 [parainstituições e grupos ou redes de estudo informais]}

Em um rápido comentário enigmático de seu ensaio undercommons, Harney e Moten afirmam que "a universidade precisa daquilo que sustenta, mas não consegue sustentar o que traz" (Edu-Factory Collective, 2009, p. 146). Estão se referindo explicitamente àqueles estudiosos críticos cujo trabalho intelectual é apropriado pela universidade em economização, para fins da reputação institucional e financiamento de pesquisas, mas que, no entanto, constrói a resistência contra as práticas gerencialistas e o paradigma neoliberal da universidade. Baseado nesta questão, Santos (2018, p. 270) discute que "o descontentamento com a universidade pelos grupos sociais que apenas recentemente conseguiram acesso a ela tende a levar a novas lutas sociais pelo direito à educação e a uma educação diferente". Especificamente, está se referindo à problemática colonial e patriarcal sobre a qual a universidade está fundada, e cujos preconceitos são cada vez mais expostos por aqueles acolhidos dentro de suas paredes sob a insígnia da inclusão. Além de raça e gênero, Santos (2018) destaca outras possíveis áreas para a decolonização, que incluem "acesso à universidade (para estudantes) e acesso a uma carreira universitária (para docentes); conteúdo de pes- 
quisa e docência; disciplinas de conhecimento, currículos e programas de estudo; métodos de ensino e aprendizagem; estrutura institucional e governança universitária; e relações entre a universidade e a sociedade em geral. A priorização política de cursos STEM na universidade, que este artigo afirmou ser inseparável da economização da universidade, transformou as artes e as humanidades críticas em vozes decoloniais. Estas vozes não apenas ressaltam a marginalização tecnocrática das artes, mas também as barreiras financeiras à participação na universidade, limitada prospecção de carreira, e a interseccionalidade do estudante de artes. As instituições categorizadas como Tipo 1 representam as vozes internas de oposição que no fim se coalesceram em práticas externas ou parainstituições. Não necessariamente demandam a abolição da universidade, mas procuram suplementar suas falhas pelo estabelecimento da oferta autônoma. Internamente, esta oferta é muitas vezes manifesta em dos grupos de leitura política, módulos extracurriculares eletivos ou redes de interesses especiais. Às vezes por necessidade, esta polifonia discordante deve se concretizar como oferta acadêmica externa.

Um exemplo típico é The Other MA (https://www.toma-art.com/ Southend on Sea, 2015-Em funcionamento) (Figura 2). Este é um programa educacional dirigido por artista com doze meses de duração baseado em Southend, na costa sudeste da Inglaterra. Depois do fechamento da oferta de artes na universidade da região, declara ser o único curso de pós-graduação em artes oferecido no condado de Essex. No primeiro caso, o TOMA é uma instituição criada por necessidade, não por protestos políticos. Entretanto, a instituição resultante gerou suas próprias formas de aprendizagem social, solidariedade e cuidado, o que demonstram cada vez mais a bancarrota do modelo neoliberal. Hall (2018, p. 198) descreveu a cultura da universidade em economização, particularmente seus requisitos implícitos de sobrecarga e competição, como "um estado semipermanente da exceção que instila a insegurança pessoal e social”. Em uma cultura como essa, o autocuidado e o cuidado com o outro podem ser compreendidos como uma forma da resistência política humanista. No nível mais básico de cuidado para com os artistas aspirantes de Essex, o TOMA tem seu próprio espaço de projeto, apoiado por financiamento do Conselhos de Artes da Inglaterra. Oferece espaços de estúdio, instalações e um programa de crítica, de palestra de artistas, de oficinas e de visitas do externas por uma taxa mensal de $£ 75$. Neste sentido, o TOMA não pode ser considerado como explicitamente anticapitalista. Entretanto, o TOMA argumenta que os valores cooperativos embasam sua estrutura e estratégia e se autoidentifica como "uma unidade familiar". Semelhante a uma cooperativa, as taxas de adesão são usadas para melhorar as instalações e a oferta da escola de artes para benefício coletivo. Uma parcela da renda do TOMA é usada pagar artistas visitantes por tutorias. Fora de seus estúdios, muitos destes artistas visitantes não teriam nenhuma outra maneira de arcar com sua subsistência, dado o número cada vez mais limitado de oportunidades remuneradas no mundo das artes ou na academia, ou 
Experiências em Ensino Autônomo de Artes no Reino Unido, 2010-até o presente

pela insistência desta última de que os professores de arte tenham qualificações acadêmicos formais como PhDs. Para o TOMA, este é um gesto coletivo contra "um mundo artístico que frequentemente enxerga os artistas no da cadeia alimentar financeira" (TOMA, 2021). Além disso, o TOMA representa uma rede de cuidado artístico, semelhante a "uma nova unidade familiar em que muitas vezes os [integrantes] dão uma ajuda ao compartilhar carona, almoço + lavagem da louça aos domingos, permuta de habilidades em sessões, organiza sessões de improviso em trens, compartilha trabalho + visita ao estúdio dos outros (sic)" (TOMA, 2021). Este ethos familiar se ampliou para uma missão social e o TOMA está explicitamente se voltando para aqueles que atualmente estão excluídos ou sub-representados no mundo artístico, como os artistas "que vivem com alguma deficiência, artistas de cor [,] LGBTQIA [ou] mulheres que estejam focadas em apoiar uma família" (TOMA, 2021). Comprovadamente, parainstituições como o TOMA não apenas suplementam a falta de oferta convencional por meio do voluntariado do terceiro setor, mas impregnam o conhecimento mestizo, ou lokvidya que expõem o imperialismo da universidade resistem a ele, em todos as suas formas. A Figura 2 resume esta síntese do relacional, do familiar e do político.

\section{Escola de Artes Polifônica Tipo 2 [A Escola de Artes como Subversidade]}

Conforme foi observado no exemplo acima, as parainstituições autônomas tendem a gerar organicamente ideologias subversivas e subjetividades contra-hegemônicas. Acompanhando Santos, podem ser compreendidas, portanto, como pluriversidades, não universidades. Ainda mais, poderiam ser compreendidas como a primeira etapa de desenvolvimento que conduz à universidade polifônica. Entretanto, esta narrativa corre o risco de substituir uma teleologia totalizadora da universidade por outra. A essência de polifonia é o pluralismo, e Santos (2017) enfatiza que as universidades polifônicas podem surgir tanto de estratégias defensivas como ofensivas. Embora as instituições do Tipo 1 acima geralmente recaiam na primeira categoria, a segunda prossegue de uma rejeição do modelo de universidade, se não um chamado definitivo por sua abolição. Estas instituições, classificadas por Santos (2017) como subversidades, são projetadas não apenas para diversificar a monocultura universitária, mas para emitir "demandas prementes por justiça cognitiva, social e histórica” (p. 390). Os princípios que sustentam a subversidade são conflito, não-conformidade, indignação, rebeldia, democracia e uma concepção freireana de educação como libertação (Freire, 1996). Apropriam-se ou ocupam "o nome 'universidade' para desenvolver processos de aprendizagem” (p. 378) que incorporam uma crítica das práticas de universidades convencionais. Sua tradição não é aquela de Humboldt, mas das universidades populares anarquistas da Europa do século XIX e da América Latina no começo do século XX. Estas universidades procuravam oferecer acesso ao conhecimento social 
negado aos trabalhadores e ensinado voluntariamente por professores comprometidos. As sessões também eram realizadas "em espaços populares e familiares para que os trabalhadores pudessem ser poupados do ambiente solene e hostil evocado por espaços da universidade convencional" (p. 397).

Todas as instituições listadas no Apêndice A como Tipo 2 poderiam ser classificadas como subversidades. The School of the Damned (https://schoolofthedamned.wixsite.com/sotd2019/about, Reino Unido, 2014-Em funcionamento) é a mais explicitamente anárquica de qualquer uma destas instituições (Figura 3 e Figura 4). Criada em Londres em 2014, desde o princípio se autoidentificou explicitamente como uma instituição do protesto. Todos os anos, integrantes são coautores de um manifesto pela instituição que invariavelmente reafirma uma oposição coletiva contra o modelo neoliberal hegemônico da universidade. Seu programa pedagógico consiste em um grupo mensal de crítica, em geral convocado para espaços organizados por artistas ou públicos, com palestrantes convidados pela escola após um processo de seleção democrático. O programa anual culmina com uma mostra de egressos. Não obstante a oposição feita pela The School of the Damned [SOTD] contra o modelo convencional de escola de artes, afirma que seu contracurso tem tanto rigor quanto a universidade MA. Duas características notáveis da SOTD precisam ser destacadas. Primeiro, mais do que uma economia de mercado em economização, a SOTD opera como uma economia do dom pedagógica (Hyde, 1983; Mauss 2002 [1954]). Através daquilo que a escola chama de modelo de bolsa-trabalho, o tempo gasto por artistas convidados para preparar e facilitar seminários na SOTD é reembolsado em espécie pelo trabalho voluntário de estudantes da SOTD. Este trabalho é empreendido em qualquer atividade em que os palestrantes convidados precisem de ajuda. Os estudantes prepararam jantares, instalaram exposições ou ajudaram a produzir ilustrações para artigos acadêmicos (Miles, 2016). Os locais para a escola foram obtidos precisamente da mesma maneira. Um espaço de ensino acima na galeria vanguardista The Horse Hospital em Londres era pago por estudantes da SOTD atuando como vigias de exposições. Um espaço de ensino acima do pub The Cock Tavern em Camden era pago por estudantes que trabalhavam em turnos no bar. Este modelo de economia do dom não apenas conecta todos os estudantes em uma relação de solidariedade, mas também forja alianças com locais e organizações parceiras. Nos últimos anos, a SOTD expandiu suas operações por todo o Reino Unido para maximizar a participação, sediando aulas em Liverpool, Londres, Sheffield, Glasgow e Newcastle. Não há nenhum motivo para este modelo não poder ser expandido internacionalmente. A segunda característica distintiva da SOTD é que o controle de seus currículos, a ideologia e a estratégia são definidos pela turma de qualquer ano determinado. Os estudantes obtêm uma vaga por meio de um processo seletivo de inscrição. Os integrantes são escolhidos pela turma do ano anterior, que então repassam o controle da escola para o ano de graduação seguinte. Isto não apenas significa que a SOTD evita perma- 
Experiências em Ensino Autônomo de Artes no Reino Unido, 2010-até o presente

nentemente a institucionalização, mas também que cada uma de suas turmas fique vinculada por uma relação ética. Em todos estes aspectos, a SOTD incorpora o que Santos chama de polifonia "itinerante" ou "errante" (p. 411), o que expande a universidade para além do controle de instituições e locais de ensino específicos.

\section{Escola de Artes Polifônica Tipo 3 [Escolas de Artes como Obras de Arte]}

Nas escolas de artes alternativas examinadas, existe uma terceira categoria de prática evidente que ultrapassa o sentido institucional da subversidade ou da pluriversidade. Estas escolas de artes alternativas, se ainda puderem ser chamadas de escolas de arte, existem além da estrutura de instituições e de currículo formal, vendo-se como mais próximas de obras de arte contemporânea e/ou performance. Conforme foi indicado, estas intervenções pedagógico-artísticas estão baseadas na virada educacional em arte contemporânea e sua teoria associada. Embora Santos não tente discutir arte contemporânea ou escolas de artes em sua obra, sua descrição da universidade polifônica se sobrepõe às teorizações de arte da virada relacional ou educacional. Em seu importante livro sobre teoria curatorial Relational Aesthetics (2002 [1998]), Bourriaud (2002 [1998], p. 14) descreveu uma transição na arte contemporânea da produção de objetos para a construção de sociabilidade através de cenários divertidos, encontros encenados ou "interstícios sociais". Estas obras de arte relacionais trazem para o primeiro plano o reino de interações humanas e seu contexto social, em vez da afirmação de um espaço simbólico independente e privado. A obra prima canônica, produzida pelo gênio artístico celebrado, incorpora este último paradigma. Em uma contradiferenciação, a arte relacional é coproduzida e imaterial, na medida em que é impossível identificar uma fonte singular de produção ou sentido artístico. Em um livro posterior, Bourriaud definiu esta modalidade criativa como Pósprodução (2002). Refletindo a transformação societal geral da produção industrial fordista para 0 trabalho imaterial pós-fordista, a arte pós-produtiva se esquiva da produção original baseada no objeto em prol da interatividade, de formas recicladas, da apropriação e de uma cultura de livre troca. Todas estas características tipificam a cultura on line na era digital. O artista é visto aqui como um remixer ou um DJ. Todas as instituições listadas no Apêndice A: Tipo 3 podem ser entendidas como remixes da escola de artes, que é desmaterializada como instituição, deixando apenas suas relações pedagógicas. Como arte pós-produtiva, estas práticas do Tipo 3 podem ser compreendidas de maneira semelhante à diferenciação feita por Negri e Revel da transição da ITA para a IAC pós-fordista. De maneira mais geral, representam o projeto de universidade popular levado aos seus limites absolutos. Em vez de um sistema em economização de marcas de universidade, satisfação de cliente e professores superstar (Cruikshank, 2019), estas obras descentram o ensino além das forças institucionais e incorporam hipótese democrática central de Jacques 
Rancière (1991) presente em The Ignorant Schoolmaster. No fim, todas produzem o que Santos (2018, p. 276) chama de "pedagogia de emergências", [que] é orientada para amplificar o sentido das sociabilidades latentes e potencialmente libertadoras, os ainda-nãos de esperança que existem no outro lado da linha abissal, o lado colonial, onde as ausências são ativamente produzidas de modo que a dominação possa prosseguir imperturbável.

Os exemplos destas anti-instituições ou escolas de artes pósprodutivas têm um caráter tão heterogêneo que seria insensato, senão impossível, resumi-los. Em vez de um resumo, um rápido exemplo ajudará a ilustrar suas tendências gerais ou estratégias pedagógicas. O @.ac, pronunciado foneticamente como attack (Reino Unido, 2014-Em funcionamento ${ }^{4}$ ), é um coletivo não-hierárquico de artistas que organizam intervenções pedagógicas em locais específicos em espaços sociais contestados. Da mesma maneira que a subversidade que ocupa o nome da universidade, o nome @.ac é roubado do sufixo genérico de endereços eletrônicos acadêmicos no Reino Unido. O @.ac afirma que se "dedica à salvação da escola de artes e, se não sua salvação, sua erradicação e substituição como forma social". Existem como uma anti-instituição nômade, sem nenhum integrante permanente. Sua atividade e adesão são negociadas projeto por projeto, aproveitando as habilidades dos atores necessários para a concretização do projeto individual. Os projetos do @.ac, quem segundo os integrantes, podem ser compreendidos como locais de teste para uma arte-educação-por-vir, em geral seguem duas estratégias. Ou transformam os espaços da universidade em economização, como conferências acadêmicas, aulas em teatros, campi universitários e sítios on line na internet em obras de arte relacionais, ou tentam recriar seminários ou aulas no estilo universitário em espaços públicos, o que pode ser acompanhado pela gratuidade ao público. Esta atividade não é simplesmente o compromisso do acadêmico radical que deseja substituir a universidade capitalista pela universidade popular. Tampouco se preocupa unicamente em subverter a imagem pública da universidade. Nos termos de Harney e Moten (2013), estes trabalhos são uma adoção do "iluminismo fugitivo" como a "revelação rompida e encantada dos comuns" (Edu-Factory Collective, 2009, p. 147). Contra o "torque autointerpelativo" do economizado, o movimento divergente e contra-hegemônico destes projetos constitui uma heurística democrática que é perpetuamente redefinida no ponto de recepção, em vez de um currículo institucional formal (Edu-Factory Collective, 2009, p. 147). 
Experiências em Ensino Autônomo de Artes no Reino Unido, 2010-até o presente

Figura 3 - Folder da School of the Damned, Turma de 2018

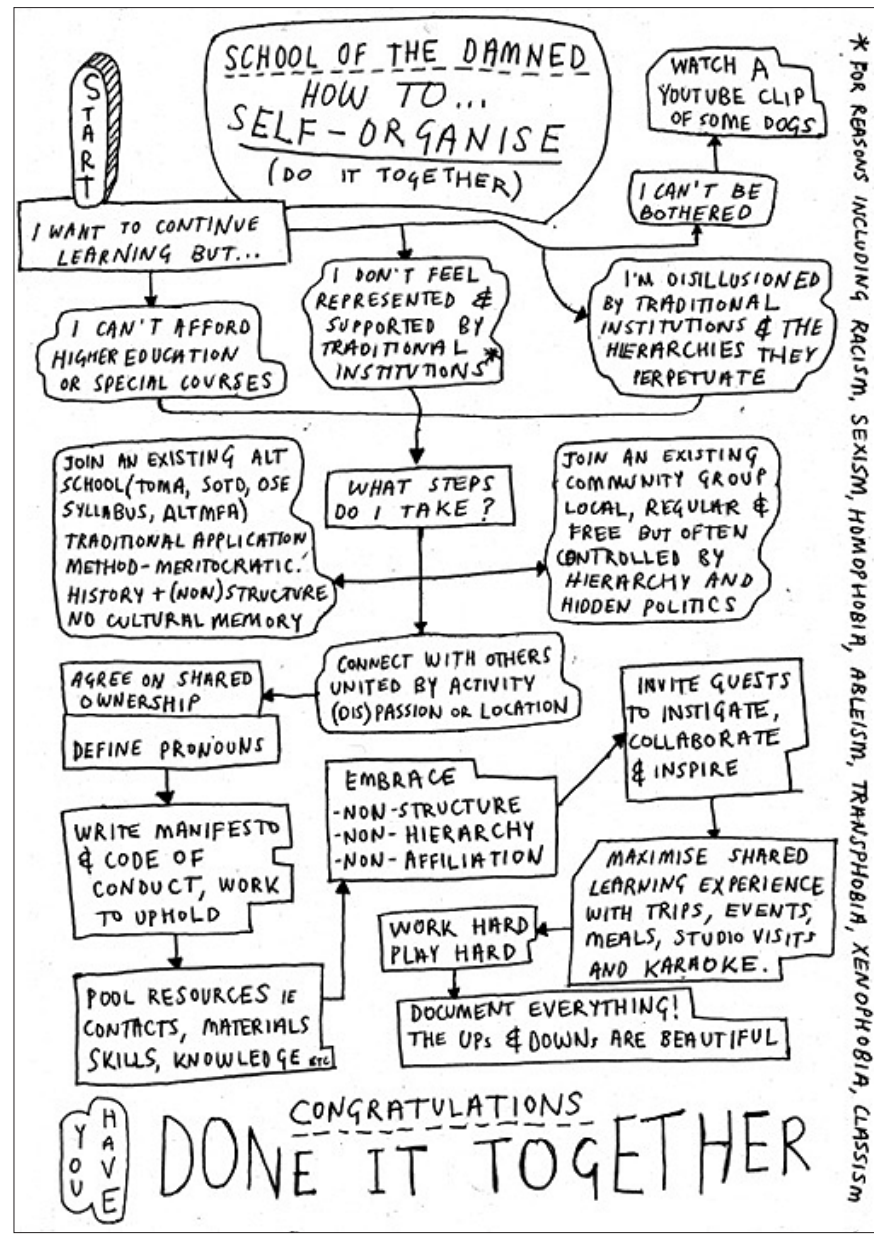

Fonte: Arquivo do autor.

\section{Conclusão: por uma pluriversidade das escolas de artes}

Frente às atuais circunstâncias, argumentam Harney e Moten, “[...] alguém só pode se esgueirar para dentro da universidade e roubar o que puder. Abusar de sua hospitalidade, contrariar sua missão, juntar-se à sua colônia de refugiados, seu acampamento cigano, estar sem pertencer, este é o itinerário do intelectual subversivo na universidade moderna” (Edu-Factory Collective, 2009, p. 145). Todas as instituições acima listadas são subversivas, pois roubam potenciais estudantes do modelo em economização e, consequentemente, ganhos. Entretanto, muitas destas instituições dependem de um corpo docente com estabilidade da universidade convencional. Considerado como uma redistribuição de 
riqueza da universidade neoliberal para suas outras excluídas, este furto subversivo de ensino também deve ser compreendido como um ato político. Ao mesmo tempo, isso é uma demonstração da precariedade financeira do ensino autônomo. Com exceção da SOTD, muito poucas destas iniciativas encontraram uma maneira sustentável de reproduzir ano após ano o ensino e a aprendizagem além do modelo de trabalho assalariado. Historicamente, muitas vezes as universidades populares se basearam no voluntariado de acadêmicos universitários compassivamente comprometidos, cuja remuneração provém de outro lugar. A troca-por-trabalho da SOTD sugere um itinerário além desta dependência da academia e tem paralelos com as redes de banco de horas, que estão sendo organizadas nacionalmente ${ }^{5}$. Este sistema de organização em rede levanta a possibilidade de uma rede similar de banco de horas, ou troca-por-trabalho, sendo estabelecida entre escolas de arte alternativas. Entretanto, o problema com muito do voluntariado do terceiro setor, no qual atualmente opera a maior parte do banco de horas, é que simplesmente fecha as lacunas na prestação estatal, amenizando seus efeitos mais prejudiciais sem responsabilizar diretamente o governo.

Mesmo assim, ao oferecer a prestação suplementar aos excluídos ou desfavorecidos, estas iniciativas educacionais autônomas estão fazendo algo muito mais significativo socialmente. Além da transferência de conhecimento artístico e da concessão de diplomas de graduação, estas instituições gradativamente impregnam hábitos de “[...] autogovernamento, de interdependência e de auxílio mútuo, embasados por valores de liberdade, igualdade e fraternidade" (Kinna, 2020). Estas são as marcas de uma sociedade anarquista em funcionamento, comprometida com a não-dominação e o indivíduo livre. Estas escolas de artes alternativas incorporam valores, incluindo diversidade, inclusividade, criticalidade, comunidade, empreendedorismo e cidadania, tudo que a universidade neoliberal prega da boca para fora apenas. Além disso, suas turmas são comprometidas com uma visão pedagógica coletiva que envergonha as concepções neoliberais de engajamento estudantil. Se, conforme Hall (2018), formos caracterizar economicamente o acadêmico da universidade alienado como ansioso, sobrecarregado, empobrecido tanto em termos econômicos como emocionais, então as subjetividades que surgem destas instituições, que recentram questões de cuidado, solidariedade, comunidade e generosidade, precisam ser consideradas como revolucionárias. Suissa (2010, p. 5) sugeriu que uma filosofia anarquista da educação suplementa perguntas padrão de "o que deveria ser ensinado, para quem, e tendo o quê em mente?” com a pergunta fundamental "por quem?". Coletivamente, estas instituições representam um desafio aos pressupostos hegemônicos de que a universidade britânica em economização (Brown, 2015; McGettigan, 2013; Edu-Factory Collective, 2009) está mais bem situada para ensinar a próxima geração de artistas. Embora os discursos governamentais descrevam a educação em artes como de baixo valor e um mau investimento pessoal, a existência destas escolas de artes alternativas demonstram um apetite continuado pela educação em artes. A economização do en- 
Experiências em Ensino Autônomo de Artes no Reino Unido, 2010-até o presente

sino superior convencional está transformando potenciais estudantes em alternativas não-mercantilizadas, se não estiver criando suas próprias escolas de artes de maneira autônoma do Estado. Muitas delas estão se tornando alternativas viáveis à escola de artes em economização, cuja lógica monetarizada corre o risco de deixar de existir. O slogan escrito acima da entrada da fábrica LIP ocupada era C'est possible: on fabrique, on vend, on se paie!" [É possível: nós produzimos, nós vendemos, nós pagamos]. Estas escolas de artes alternativas questionam seriamente se um ensino de graduação e de pós-graduação em artes não poderiam ser facilmente substituído por um sistema de autoeducação conduzido por um artista o pelo mundo artístico. Isso representaria artistas uma ITA unificando artistas, o mundo das artes e o ensino de artes.

Ao ser uma heterogeneidade de comunidades intencionais, coletivamente estas instituições também representam a possibilidade de surgimento de ITAs, que poderiam se aproximar do modelo de universidade autônoma global do projeto Edu-Factory. Dito isso, esta multidão nascente de escolas de artes ainda não se iguala à pluriversidade pós-abissal e polifônica de Santos. Das instituições listadas, somente a Network 11 poderia genuinamente afirmar que está impregnando as epistemologias do Sul. Entretanto, os chamados para decolonizar a universidade geraram debates no setor. Em 22 de janeiro de 2020 foi publicada uma edição especial da revista da Association for Art History, convocando para “Decolonizar a História da Arte" (Grant; Price, 2020). Estes debates na academia indubitavelmente irão gerar parainstituições em suas margens ou irão se transformar em prioridades de subversidades como a FBU. A partir do advento de práticas de crítica institucional no fim da década de 1960, muito foi escrito a respeito do caráter burguês patriarcal branco do mundo artístico. Mesmo assim, aparentemente muito pouca mudança concreta está ocorrendo, pelo menos no Reino Unido, especialmente em relação à inclusão racial. Claramente, há muito trabalho a ser feito pelo setor acerca disso. $O$ último relatório de diversidade do Arts Council of England [ACE], Equality, Diversity and the Creative Case (ACE, 2020), publicado em 18 de fevereiro de 2020, pinta um quadro deprimente, mas cuidadosamente previsível referente tanto à falta de diversidade como à inércia institucional a respeito de mudanças significativas em algumas das frentes de representação de BAME [comunidade de pessoas pretas, asiáticas e minoritárias] e pessoas com deficiência. Das 663 organizações de artes no portfólio nacional e nos 21 museus, os trabalhadores BAME totalizavam $12 \%$ da força de trabalho, enquanto apenas 5\% dos funcionários da galeria não eram brancos. Como resposta a isso, o diretor do ACE e ex-diretor da Tate Gallery, Sir Nicholas Serota, formulou os seguintes chavões sinceros:

\footnotetext{
A diversidade de pensamento, experiência e perspectiva é vital e, portanto, a inclusividade e a relevância são princípios orientadores da estratégia do Arts Council para os próximos dez anos (Serota apud ACE, 2020, p. 3).
}

Mesmo assim, de acordo com dados setoriais da Higher Educa- 
tion Statistics Agency para o ano letivo 2014/5 - 2018/19, apenas 16\% dos alunos que estudam artes criativas não eram brancos, em comparação com $26 \%$ de estudantes não-brancos em geral.

Situados nas linhas de frente do conflito entre o saber científico e o artesanal, e entre a mercantilização do trabalho intelectual e a rejeição do conhecimento considerado socioeconomicamente inútil (Santos 2018), estas experiências de ensino e aprendizagem merecem maior atenção acadêmica. Representam espaços onde a conscientização trabalhista está alinhada com a organização profética da multidão. Reafirmam a missão cidadã original da universidade para a transformação social de cidadãos e comunidades (NUS/UUK, 2015), enquanto também invertem a degeneração do homo-politicus em homo-oeconomicus (Brown, 2015). Embora seja necessário desenvolver mais trabalhos para alinhar estes modelos radicais emergentes com as epistemologias do Sul, possivelmente o ato de mapear suas vozes polifônicas neste artigo começa o processo de formar a aliança crítica entre defensores da busca de conhecimento "sem valor de mercado" e os defensores da "ciência pós-abissal” que Santos reconhece como pré-condição para a pluriversidade (Santos 2018, p. 278).

Figura 4 - Espumante da Graduação da School of the Damned (2014)

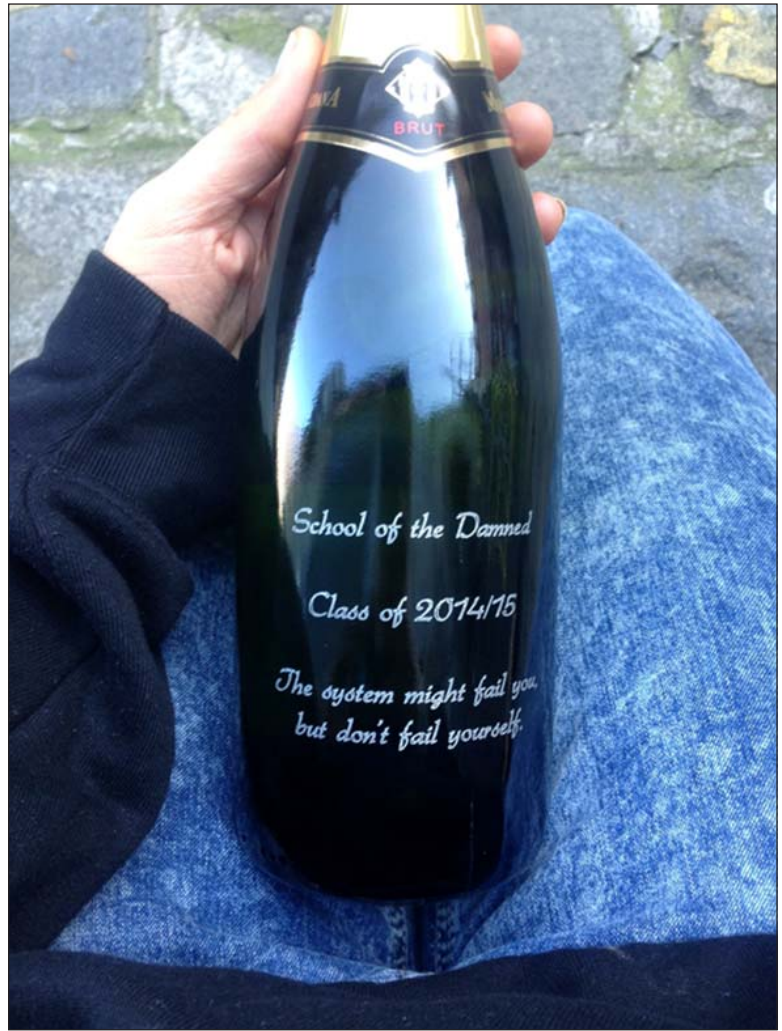

Fonte: Arquivo do autor. 
Experiências em Ensino Autônomo de Artes no Reino Unido, 2010-até o presente

\section{Apêndice A}

\section{Escola de Artes Polifônica Tipo 1 [Parainstituições e grupos ou redes de estudo informais]}

- Art and Critique (Londres, 2015-2019) era uma rede de artistas coordenada por pares dedicada ao engajamento crítico com a pesquisa teórica em artes, assumindo a forma de um grupo da leitura realizado em dois centros sociais de Londres, The Field (http://thefieldnx.com) e London Action Resource Centre (http://larc.space/).

- Art / Work Association (https://artworkassociation.org/)_Londres 2011Em funcionamento) é uma "associação de artistas e trabalhadores criativos e um programa autogerado de palestras, projeções, seminários, grupos de leitura, oficinas e sessões de feedback crítico, concebida como um fórum para intercâmbio entre pares". Um evento recente incluiu palestras da diretora cinematográfica Elaine Constantim e da artista Dominic de Luton, em parceria com os prestadores estabelecidos City \& Guilds of London Art School e a University of the Arts, Londres.

- Conditions (https://conditions.studio/Croydon, 2018-Em funcionamento) foi criada para oferecer estúdios de baixo custo para artistas emergentes. Utilizando financiamento do Croydon Council e um esquema da Mayor of London Creative Enterprise Zone, os aluguéis do estúdio são drasticamente reduzidos. Em troca, espera-se que os proprietários dos estúdios "busquem alternativas ao atual estado da arte e ensino de artes na Grande Londres”.

- Evening Class é um ambiente de aprendizagem auto-organizado sediado Poplar, East London. Não existe processo seletivo nem qualquer outra barreira à participação. $\mathrm{O}$ grupo se reúne todas as terças e quintas-feiras para desenvolver um programa determinado pelos integrantes do grupo, cada uma pagando $£ 35$ ao mês para sustentar as atividades do grupo.

- Fairfield International (http://fairfieldinternational.co.uk/\#, Saxmundham, Suffolk, 2013-Em funcionamento), é uma escola de artes residencial coordenada por artistas concebida pelo artista Ryan Gander, discutida acima.

- Feral Art School (https://www.feralartschool.org/Hull, 2018-Em funcionamento) foi fundada depois do fechamento da Hull School of Art in Design em 2018. Inspirada pelo trabalho de Mike Neary e Joss Winn ao fundarem o Social Sciences Centre (https://socialsciencecentre.org.uk/, Lincoln 2011-2019), a Feral foi criada como uma cooperativa de trabalhadores. As taxas de matrícula são acessíveis em comparação com a oferta de cursos de curta duração de universidades neoliberais, e as taxas revertem diretamente para sustentação da cooperativa e oferecer salário para seus funcionários, muitos deles demitidos após o fechamento da Hull School of Art and Design (Goodman; Hudson-Miles; Jones, 2021).

- The Margate School (https://www.themargateschool.com/, Margate, 2015-Em funcionamento) oferece um MA em Belas Artes, juntamente com um portfólio de cursos breves. Seu MA é formalmente acreditado 
por um parceiro fora do Reino Unido, a Normandy L'École Supérieure d'Art na Normandia, e o curso possui 120 créditos inteiramente transferíveis sob o European Credit Accumulation and Transfer Scheme [ECTS]. As taxas variam de $£ 1.650$ a $£ 4.000$, dependendo se os estudantes em potencial desejam ter um estúdio ou estão baseados em Margate e em East Kent. A Margate School é coordenada por uma empresa sem fins lucrativos.

- The New Independent Art School of Hastings (https://www.niash.org/, Hastings, 2013-2015) era uma iniciativa sem fins lucrativos conduzida por artistas, desenvolvida pelos artistas Dean Kenning e Kate Renwick durante uma residência dos artistas. Durante um ano, transformou o terceiro andar do centro comunitário Rock House em uma plataforma para "oficinas, leituras, eventos coletivos de educação, exposições, residências de artistas e diversas festas inesquecíveis".

- The School for Civic Imagination (https://www.cca-glasgow.com/ programme/school-for-civic-imagination, Glasgow, 2017-Em funcionamento) é um programa de aprendizagem informal sediado no Centre for Contemporary Art. Compreende uma série de palestras e oficinas buscando solidificar as redes criativas de profissionais de Glasgow e facilitar "um maior desenvolvimento de conexões mais profundas entre a prática das artes socialmente engajada e a vida cidadã".

- The Other MA (https://www.toma-art.com/ Southend on Sea, 2015-Em funcionamento), discutidas em detalhes acima.

- Turps Banana https://www.turpsbanana.com/art-school) Londres 2012-Em funcionamento) foi fundada pelo artista Marcus Harvey em Londres em 2012 como um programa de pintura coordenado por artistas. Para Harvey, "o objetivo escola é fazer o que muitas escolas de artes costumavam fazer e não fazem mais, e isso é oferece oportunidade para egressos darem continuidade à exploração da pintura" (ColemanSmith, 2015, p. 62). Opera tanto como um programa do estúdio como um curso por correspondência. O curso em estúdio custa $£ 6.500$ ao ano, o que faz dele o mais caro dos modelos alternativos de escolas de arte. Por essa taxa, os estudantes conseguem um espaço de estúdio próximo a Elephant and Castle, South London, acessível 7 dias por semana, 24 horas por dia, e um currículo com duração de um ano que se aproxima do ano letivo. Turps Banana também oferece um curso por correspondência por $£ 1.750$ ao ano em que os estudantes aprendem on line com um artista-mentor designado.

\section{Escola de Artes Polifônica Tipo 2 [A Escola de Artes como Subversidade]}

- Alt-MFA (http://altmfa.blogspot.com/ London) afirma ter sido o primeiro modelo de oferta alternativa de arte fundado no país (Macpherson, 2015). Fundado em 2010, incorporam aspectos tanto de parauniversidade como de subversidade, modelando-se explicitamente no MFA (Master of Fine Arts), mas oferendo isso mediante métodos conduzidos por pares, horizontais e experimentais. Sua estrutura institucional evo- 
Experiências em Ensino Autônomo de Artes no Reino Unido, 2010-até o presente

luiu de grupos da leitura, palestras de artistas e críticas de estúdio para pedagogias mais experimentais que abrangem copesquisa temática, exposições, caminhar e fazer refeições juntos. Este último é enfatizado como um aspecto particularmente central da escola. A partir da "estética relacional” (Bourriaud, [2002] 1998) da década de 1990, artistas como Rirkrit Tirivanija vêm destacando a comensalidade como um ato político. Da mesma forma, ao analisar a função do comer juntos na Grécia após a crise financeira, Sutton (2018) argumentou recentemente que incorpora "os valores da vida: solidariedade, respeito mútuo e uma sociedade baseada em valores humanos", e pode ser discutido que incorpora uma crítica imanente de economização neoliberal que ele considera como política e pedagógica.

- Islington Mill Art Academy (https://www.islingtonmill.com/, Manchester 2008-Em funcionamento) foi criada imediatamente antes da Revisão Browne (2010), mas está incluída nesta lista devido à sua escala e sucesso. Desde sua criação na próspera comunidade criativa de Islington Miçç, a IMAA se desenvolveu em uma escola de artes genuinamente viável e, consequentemente, subversiva, alternativa à escola de artes neoliberal, se não às relações societais neoliberais em geral. Situada entre as cidades de Salford e Manchester, a IMAA é um entre os muitos ocupantes criativos de um moinho vitoriano reaproveitado. Embora recentemente tenha recebido financiamento do ACE, o modelo financeiro de Islington Nill é sustentável e autofinanciado. Os ganhos são gerados pelo aluguel de espaços de estúdio e os inquilinos pagam aluguel através da renda gerada por sua prática pessoal e das vendas nas exposições sediadas no Moinho. Renda suplementar é oriunda de hospedagem no complexo. Os residentes da IMAA alugam estúdios e refletem toda a gama de indústrias criativas, incluindo artistas visuais, curadores, bandas de música pop, DJs, designers, coletivos queer. A Art Academy é totalmente gratuita, sem nenhum currículo formal, e é composta por um programa de oficinas, palestras, críticas e apoio de pares oferecidos pelos residentes do Islington Mill. De fato, Islington Mill é uma ecologia criativa autossustentada de ajuda mútua e coaprendizagem que transcende currículos institucionais. A publicidade de Islington Mill afirma que a organização é inspirada pelo Situationist International e dedicada a atuar como "um catalizador para o ato criativo".

- Network 11 (https://ntwrk11.wordpress.com/about/, London, 2015Em funcionamento) é um grupo de aprendizagem com pares dedicado a embasar "os posicionamentos de artistas de cor e comunidades LGBT baseados no Reino Unido". Como tal, representa a primeira organização de artes alternativa explicitamente pós-abissal neste levantamento.

- Open School East (https://openschooleast.org/ Londres e Margate, 2013-Em funcionamento) foi uma tentativa de produzir uma escola de artes que fosse "flexível, autodirigida, sociável e gratuita" (Thorne, 2017, p. 25). Assumiu a forma de uma chamada aberta aos participantes, dos quais dez a quinze artistas receberam gratuitamente a taxa de matrícula e um espaço de estúdio para desenvolver sua prática durante um ano. Agora se expandiu para um Programa Associado com um ano de duração para artistas emergentes de diferentes formações, um Programa 
para Jovens Associados para jovens de 16 a 18 anos de idade, a Despacito Art School para crianças de 5 a 12 anos de idade, e o "Programa Público" oferecido pela OSE para facilitar "interações entre a comunidade artística, a vizinhança local e o público ampliado” (OSE, 2019). Tudo isso continua gratuito, sustentado por inscrições para financiamento nacional em artes. O Ano Piloto 2013-14, inclusiva as excursões a pé em Kings Cross, Londres, conduzidas pelo artista Richard Wentworth. Em 2019, o Programa Associado da OSE realizou uma série de oficinas culinárias gratuitas no Centro de Educação de Adultos, Margate, que não somente ensinou habilidades culinárias como levou à abertura de uma cantina comunitária no centro.

- The School of the Damned (https://schoolofthedamned.wixsite.com/ sotd2019/about, UK, 2014-Em funcionamento), discutida acima.

- The Anti-MA (Brighton, 2019-Em funcionamento) é um programa fundado muito recentemente de aprendizagem conduzida por pares que se reúne mensalmente no Coachwerks artspace. Continua apesar do recente lockdown pela pandemia de COVID-19 e seu recente manifesto foi elaborado em coautoria via Zoom. Ao enfatizar a coaprendizagem, a horizontalidade, a igualdade, a oportunidade e a amizade, este manifesto incorpora um conjunto de valores que deve ser considerado subversivo em comparação com o modelo hegemônico.

\section{Escola de Artes Polifônica Tipo 3 [Escolas de Artes como Obras de Arte]}

- @.ac, pronunciado foneticamente como attack (http://www.attackdotorg.com/, Reino Unido, 2014-Em funcionamento), discutido acima.

- The Alternative Art College (https://alternativeartcollege.co.uk/, Lincoln 2011-2017) foi fundado como "um protesto pragmático do ensino superior" contra a economização neoliberal da educação de artes. O AAC afirma que o ensino de artes representa "não apenas um processo para ganho de capital e uma carreira, mas a via para mudança social ao questionar o mundo ao nosso redor. Aprender com e de arte é uma tensão com o capital e é nossa prerrogativa destacar esta tensão”. O AAC era uma série de intervenções artísticas e palestras de artistas esporádicas e gratuitas que agora foram documentadas em seu website, que também contém também um recurso valioso de pedagogia da arte alternativa mais ampla.

- DIY Art School (https://www.facebook.com/DiyArtSchool/, Manchester 2013-14), é uma plataforma on line "em fluxo constante", criada como uma "plataforma de sobrevivência” e espaço de visibilidade para graduados em artes.

- Nomad Art School (https://nomadgallery.weebly.com/, Reino Unido 2015-Em funcionamento) "é uma Escola de Artes aberta, permanente, gratuita e itinerante, onde os artistas oferecem seu conhecimento, pessoal ou virtualmente: sem plano de estudos, sem seleção, sem acreditação [...] Consequentemente, não há nenhum certificado no fim do curso porque não é um curso, e assim nunca termina". 
Experiências em Ensino Autônomo de Artes no Reino Unido, 2010-até o presente

- The Precarious University (http://www.lcac.org.uk/wp/2016/05/11/ the-precarious-university/, Manchester, 2016-Em funcionamento) é uma série de oficinas e palestras ad hoc em andamento organizadas como gestos de desvio em espaços públicos e em simpósios acadêmicos formais.

- The Silent University (https://www.tate.org.uk/about-us/projects/ silent-university, Londres, Hamburgo, Estocolmo, Ruhr, 2012-Em funcionamento) era um projeto criado pelo artista turco Ahmet Ögut e posteriormente foi publicado como um livro do mesmo nome. Este projeto incluía uma residência de um ano de duração na Tate Gallery, Londres. The Silent University procura trabalhar para uma pedagogia transversal que busca oferecer uma "plataforma de intercâmbio de conhecimento baseado na solidariedade por pessoas deslocadas e migrantes forçados [...] conduzida por um grupo de professores, consultores e pesquisadores". Especificamente, conecta docentes universitários migrantes ou refugiados com as estruturas da academia que seu status lhes negaria de outra maneira. O termo silencing se refere a esta negação de uma voz.

- The University of Strategic Optimism (2011) (https://universityforstrategicoptimism.wordpress.com/, Londres 2011-14) não continua mais em atividade, mas suas ações foram preservadas como um website e também publicaram suas posições em um volume acadêmico. Embora não se identificando explicitamente como uma escola de artes alternativa, está incluída nesta lista devido a suas táticas de oferecer palestras inaugurais como peças de performance específicas ao local, semelhante ao Situationist International. Por exemplo, a aula inaugural que criticava a economização da universidade neoliberal foi feita em uma avenida fora de uma filial do banco Lloyds TSB na avenida Borough, Borough, Londres. A segunda aula foi feita caminhando por um supermercado Tesco.

Traduzido por Ananyr Porto Fajardo

Recebido em 16 de agosto de 2021 Aprovado em 19 de novembro de 2021

\section{Notas}

1 Disponível em: https://www.newcontemporaries.org.uk/. Acessível em: 1 ago. 2021.

2 Disponível em: https://vidyaashram.org/. Acessível em: 1 ago. 2021.

3 Disponível em: http://www.freeblackuni.com. Acessível em: 1 ago. 2021.

4 Disponível em: http://www.attackdotorg.com/. Acessível em: 1 ago. 2021.

5 Disponível em: https://timebanking.org/. Acessível em: 1 ago. 2021.

\section{Referências}

ACE. Arts Council of England. 'Equality, Diversity and the Creative Case'. Arts Council England, Manchester, 2020. Available at: https://www.artscouncil.org. uk/sites/default/files/download-file/ACE_DiversityReport_V11.pdf. Accessed: 1 Aug. 2021. 
Hudson-Miles

ALTHUSSER, Louis. For Marx. Trans. Ben Brewster. London: NLB, 1965.

ALTHUSSER, Louis. Lenin and Philosophy, and Other Essays. Trans. Ben Brewster. London: NLB, 1971.

ARDAY, Jason; MIRZA, Heidi Safia (Ed.). Racism, Whiteness and Decolonising the Academy. London: Palgrave, 2018.

AUGAR REVIEW. Department for Education. 'Post-18 review of education and funding: independent panel report'. UK Government, London, 30th May 2019. Available at: https://www.gov.uk/government/publications/post-18-review-of-education-and-funding-independent-panel-report. Accessed on: 1 Aug. 2021.

BARR, Nicholas. 'Milton Friedman and the Finance of Higher Education'. In: CORD, Robert A.; HAMMOND, Daniel J. (Ed.). Milton Friedman: Contributions to Economics and Public Policy. New York; Oxford: Oxford University Press, 2016. p. 436-463.

BARR, Nicholas et al. 'The US College Loans System: Lessons from Australia and England'. Economics of Education Review, v. 71, p. 32-48, 2019.

BECK, John; CORNFORD, Matthew. The Art School And The Culture Shed. Kingston; Thames: Kingston University, 2014.

BOLTON, Paul. 'Student Loan Statistics'. House of Commons Library, 23rd June 2021. Available at: https://commonslibrary.parliament.uk/research-briefings/ sn01079/. Accessed on: 1 Aug. 2021.

BOLTON, Paul; HUBBLE, Susan. 'Higher Education Tuition Fees in England'. House of Commons Library, 25th June 2018. Available at: https://commonslibrary.parliament.uk/research-briefings/cbp-8151/. Accessed on: 1 Aug. 2021.

BOLTON, Paul; HUBBLE, Susan. 'Update on the Sale of Student Loans'. House of Commons Library, 16th September 2020. Available at: https://commonslibrary. parliament.uk/research-briefings/cbp-8348/. Accessed on: 1 Aug. 2021.

BOURRIAUD, Nicolas. Relational Aesthetics. Dijon: Les Presses du réel, 2002. [1998].

BOURRIAUD, Nicolas. Postproduction. Trans. Jeanine Herman. New York: Lukas \& Sternberg, 2005.

BRITISH ACADEMY. 'The Landscape For Humanities and Social Sciences In Higher Education: The Current Picture'. British Academy Document, n. 84, 2018. Available at: https://www.thebritishacademy.ac.uk/documents/84/TheLandscapeForHumanitiesAndSocialSciencesInHigherEducation_0.pdf. Accessed on: 1 Aug. 2021.

BROWN, Wendy. Undoing the Demos. New York: Zone, 2015.

BROWNE REVIEW; DBIS. Department for Business, Innovation, and Skills. Securing a Sustainable Future for Higher Education: An Independent Review of Higher Education Funding and Student Finance. UK Government, London, 12th October, 2010. Available at: https://www.gov.uk/government/publications/the-brownereport-higher-education-funding-and-student-finance. Accessed on: 1 Aug. 2021.

CRUIKSHANK, Justin. 'The Feudal University in the Age of Gaming the System'. Social Epistemology Review and Reply Collective, v. 8, n. 8, p. 12-14, 2019.

ECONOMIST, The. 'Special Report - Museums: The Bilbao Effect. The Economist, London v. 409, n. 8867, Dec. 21, 2013.

EDU-FACTORY COLLECTIVE. Towards a Global Autonomous University. New York: Autonomedia, 2009.

FERGUSON, Kate. 'Corbyn Faces Calls to Resign for Reneging on Promise to Write Off £100bn Student Debt After Two Shadow Ministers are Caught Publicly Boas-

Educação \& Realidade, Porto Alegre, v. 46, n. 4, e118205, 2021. 
Experiências em Ensino Autônomo de Artes no Reino Unido, 2010-até o presente

ting about the Plans'. Mail Online, 25th July 2017. Available at: https://www.dailymail.co.uk/news/article-4728138/Nick-Gibb-says-Corbyn-apologise-studentdebt.html. Accessed on: 1 Aug. 2021.

FISHER, Mark. Capitalist Realism. New York: Zero, 2009.

FREIRE, Paulo. Pedagogy Of The Oppressed. London: Penguin, 1996. [1970].

FRIEDMAN, Milton. ‘The Role of Government in Education'. In: SOLO, R. A. (Ed.). Economics and the Public Interest. New Brunswick: Rutgers University Press, 1955. P. 123-144

FRIEDMAN, Milton; KUZNETS, Simon. Income from Independent Professional Practice. New York: National Bureau of Economic Research, 1945.

FULL FACT. 'Student Debt: What Did Labour Say?'. Full Fact, London, 22nd September 2017. Available at: https://fullfact.org/education/student-debt-what-didlabour-say/ Accessed on: 1 Aug. 2021.

GOODMAN, Jackie; HUDSON-MILES, Richard; JONES, Jayne. 'What Artists Want, What Artists Need: A Critical History of the Feral Art School, Hull, UK 2018Present'. International Journal of Art \& Design Education, 2021. DOI: 10.1111/ jade.12376.

GRANT, Catherine; PRICE, Dorothy. 'Decolonize Art History'. Art History, v. 43, n. 1, p. 9-66, 2020.

HALL, Richard. The Alienated Academic: The Struggle for Autonomy Inside the Academy. London: Palgrave, 2018.

HARDT, Michael; NEGRI, Antonio. Multitude. London; New York: Penguin, 2006.

HARNEY, Stefano; MOTEN, Fred. The Undercommons: Fugitive Planning and Black Study. New York: Minor Compositions, 2013.

HARRIS, Gareth. 'UK Government Approves 50\% Funding Cut For Arts and Design Courses'. The Art Newspaper, 22nd July 2021. Available at: https://www.theartnewspaper.com/news/uk-government-sanctions-50-funding-cut-for-arts-anddesign-courses. Accessed on: 1 Aug. 2021.

HC DEB. House of Commons Debate. 'Tuition Fees', v. 684: debated, Monday 16th November, 2020. Available at: https://hansard.parliament.uk/Commons/2020-11-16/debates/7BF8890F-3E72-44BC-B260-49E74D0B91C7/TuitionFees. Accessed on: 1 Aug. 2021.

HYDE, Lewis. The Gift: Imagination and the Erotic Life of Property. New York: Vintage, 1983.

KINNA, Ruth. 'Anarchism And Education: The Rebel City Teaching Project'. Political Studies Association, London, 9th December, 2020. Available at: https://www. psa.ac.uk/psa/news/anarchism-and-education-rebel-city-teaching-project. Accessed on: 1 Aug. 2021.

KOSMAOGLOU, Sophia. 'Festival of Alternative Arts Education'. 2021a. Available at: https://videomole.tv/festival/. Accessed on: 1 Aug. 2021.

KOSMAOGLOU, Sophia. 'Alternative Art Schools and Networks'. 2021b. Available at: https://videomole.tv/alternative-art-education/. Accessed on: 1 Aug. 2021.

LAZZARATO, Maurizio. 'Immaterial Labor'. In: HARDT, Michael; VIRNO, Paulo (Ed.). Radical Thought in Italy: A Potential Politics. Minneapolis; London: University of Minnesota Press, 1996. P. 133-147.

LOTRINGER, Sylvère; MARAZZI, Christian. Autonomia: Post-Political Politics. Los Angeles: Semiotext(e), 2007. 
MAUSS, Marcel. The Gift: Forms And Functions Of Exchange In Archaic Societies. London: Routledge, 2002 [1954].

McGETTIGAN, Andrew. The Great University Gamble: Money, Markets and the Future of Higher Education. London: Pluto, 2013.

McGETTIGAN, Andrew. 'English HE - An Overview'. In: UCU CRADLE TO THE GRAVE CONFERENCE, 2016, London. Presentation London: TUC Congress House, 6 Feb 2016. Available at: https://www.ucu.org.uk/media/7876/UCU-Cradle-toGrave-Andrew-McGettigan-presentation-Feb-16/ppt/ucuctg16_andrewmcgettigan_febl6.pptx. Accessed on: 1 Aug. 2021 .

MILES, Richard. 'Illustration, Education, Revolution: Lessons from Rancière for the C21st Illustration Student'. Varoomlab, n. 4, p. 25-40, 2016.

MORGAN, John. 'Ministers Consider Loan Changes and Minimum Entry Bar in England'. Times Higher Education, Jan 21st, 2021a. Available at: https://www. timeshighereducation.com/news/ministers-consider-loan-changes-and-minimum-entry-bar-inengland. Accessed on: 1 Aug. 2021.

MORGAN, John. 'Cutting English Fees or Student Numbers 'on Treasury Agenda'. Times Higher Education, March 15th, 2021b. Available at: https://www.timeshighereducation.com/news/cutting-english-fees-or-student-numbers-treasuryagenda. Accessed on: 1 Aug. 2021.

NUS / UUK. National Union of Students / Universities UK. 'Breaking Down the Barriers to Student Opportunities and Youth Social Action'. 2015. Available at: https://www.universitiesuk.ac.uk/policy-and-analysis/reports/Documents/2015/ breaking-down-the-barriers.pdf. Accessed on: 1 Aug. 2021.

O'LEARY, John. 'Enrolment Falls in Arts and Humanities Subjects'. The Times, Sep 25th, 2018. Available at: https://www.thetimes.co.uk/article/good-university-guide-2019-enrolment-falls-in-arts-and-humanities-subjects-h8g7gbn90. Accessed on: 1 Aug. 2021

O'NEILL, Paul; WILSON, Mick. Curating and the Educational Turn. Amsterdam: De Appel; Open Editions, 2005.

PARAR BOLONHA. Discussion. The Contribution Of 'Rete Per L'autoformazione' (Italy)'. 'Edu-factory.Org', 30th April 2007. Available at: http://pararbolonha.blogspot.com/2007/04/edu-factoryorg-discussion-by-rete-per.html?m=l. Accessed on: 1 Aug. 2021.

RANCIÈRE, Jacques. The Ignorant Schoolmaster. Trans. Kristen Ross. Stanford: Stanford University Press, 1991.

READINGS, Bill. The University in Ruins. Cambridge, Massachusetts: Harvard University Press, 1996.

ROGOFF, Irit. ‘Turning'. e-flux, \#00, November, 2008. Available at: http://www.eflux.com/journal/00/68454/editorial/. Accessed on: 1 Aug. 2021.

RUSSELL GROUP. Opening Doors: Understanding and Overcoming the Barriers to University Access. 2015. Available at: https://russellgroup.ac.uk/policy/publications/opening-doors-understanding-and-overcoming-the-barriers-to-university-access/. Accessed on: 1 Aug. 2021.

RUSSELL GROUP. 'Pathways to Potential' Access'. 2020 Available at: https://russellgroup.ac.uk/policy/publications/opening-doors-understanding-and-overcoming-the-barriers-to-university-access/. Accessed on: 1 Aug. 2021.

RYDER, Andrew. 'The Theory And Practice Of Italian Workerism'. International Socialist Review, n. 107, Autumn/Winter 2017. Available at: https://isreview.org/ issue/109/theory-and-practice-italian-workerism. Accessed on: 1 Aug. 2021 .

Educação \& Realidade, Porto Alegre, v. 46, n. 4, e118205, 2021. 
Experiências em Ensino Autônomo de Artes no Reino Unido, 2010-até o presente

SANTOS, Boaventura de Sousa. Decolonising the University: The Challenge of Deep Cognitive Justice. Newcastle: Cambridge Scholars Publisher, 2017.

SANTOS, Boaventura de Sousa. The End Of The Cognitive Empire: The Coming of Age of Epistemologies of the South. Durham; London: Duke University Press, 2018.

SCHOOL OF THE DAMNED. 'Britain's Free Art Schools are Making an Arts Education Accessible Again'. 2015. Available at: https://schoolofthedamnedarchive. tumblr.com/2015. Accessed on: 1 Aug. 2021.

SUISSA, Judith. Anarchism and Education: A Philosophical Perspective. Oakland: PM Press, 2010.

SUTTON, David. 'Becoming an "Other Human:" On the Role of Eating Together in Crisis Greece'. EuropeNow, 2018. Available at: https://www.europenowjournal. org/2018/09/04/becoming-an-other-human-on-the-role-of-eating-together-incrisis-greece/. Accessed on: 1 Aug. 2021.

SWAIN, Harriet. Payback Time: Academic's Plan To Launch Free Black University In UK'. Guardian, London, 2020. Available at: https://www.theguardian.com/ education/2020/jun/27/payback-time-academics-plan-to-launch-free-black-university-in-uk. Accessed on: 1 Aug. 2021.

THORNE, Sam. School: A Recent History of Self-Organised Art Education. New York: Sternberg Press, 2017.

TOMA, The Other Ma. About TOMA. 2021. Available at: https://www.toma-art. com/about. 2021. Accessed on: 1 Aug. 2021.

TRONTI, Mario. 'Factory and Society'. Operaismo in English, 2013. [1962]. Available at: https://operaismoinenglish.wordpress.com/2013/06/13/factory-and-society/. Accessed on: 1 Aug. 2021.

UNIVERSITY FOR STRATEGIC OPTIMISM. Undressing the Academy: Or, the Student Handjob. New York: Minor Compositions, 2011.

WOOLCOCK, Nicola. 'University Students Ditch Arts Degrees and Opt For Medicine'. The Times, Feb 4th, 2021. Available at: https://www.thetimes.co.uk/article/ university-students-ditch-arts-degrees-and-opt-for-medicine-w63vnzrxd. Accessed on: 1 Aug. 2021.

Richard Hudson-Miles é Professor Adjunto em Culturas do Design na De Montfort University, Leicester, Reino Unido e Pesquisador de Pós-Doutorado no Yale Paul Mellon Centre for British Art, Londres. Sua pesquisa opera nas interseções de história do design, estética continental, teoria social radical e sociologia da educação. Logo irá publicar uma introdução ao trabalho de Jacques Rancière para a editora Routledge.

ORCID: https://orcid.org/0000-0002-1055-4459

E-mail: richard.hudson-miles@dmu.ac.uk

Editor-responsável: Luís Armando Gandin

Este é um artigo de acesso aberto distribuído sob os termos de uma Licença Creative Commons Atribuição 4.0 Internacional. Disponível em: <http:// creativecommons.org/licenses/by/4.0>. 